\title{
Tamanhos de recipientes e o uso de hidrogel no estabelecimento de mudas de espécies florestais nativas ${ }^{1}$
}

\author{
Tiago Cavalheiro Barbosa ${ }^{2,4}$, Ricardo Ribeiro Rodrigues ${ }^{3}$ e Hilton Thadeu Zarate do Couto ${ }^{3}$
}

Recebido: 5.07.2013; aceito: 19.09.2013

\begin{abstract}
Container sizes and the use of hydrogel in the establishment of seedlings of native forest species). This study evaluated survival and early growth of 30 native species, planted in the containers tubetão $\left(290 \mathrm{~cm}^{3}\right)$, tubetinho $\left(56 \mathrm{~cm}^{3}\right)$, and bandeja $\left(9 \mathrm{~cm}^{3}\right)$, with and without use of hydrogel at planting. The species contemplated all successional groups and 17 botanical families. As a result, we concluded that the species from tubetão had lower percentages of mortality, followed by tubetinho and bandeja. Some species produced in bandeja showed lower mortality, when compared to those of tubetinhos, showing the possibility of its use, with managements that ensure the initial survival of the seedlings. The hydrogel did not affect the establishment and growth of seedlings, in all containers. We concluded that ensuring the establishment of seedlings, there were no differences between containers, stressing that different managements might reduce costs in the restoration with total planting.
\end{abstract}

Key words: diversity, mortality of seedlings, restoration of degraded areas, survival rate

RESUMO - (Tamanhos de recipientes e o uso de hidrogel no estabelecimento de mudas de espécies florestais nativas). O presente estudo objetivou avaliar a taxa de sobrevivência e crescimento inicial de 30 espécies arbóreas nativas, de mudas acondicionadas em tubetão $\left(290 \mathrm{~cm}^{3}\right)$, tubetinho $\left(56 \mathrm{~cm}^{3}\right)$ e bandeja $\left(9 \mathrm{~cm}^{3}\right)$, com e sem utilização de hidrogel no plantio. As espécies pertenciam a todos os grupos sucessionais e a 17 famílias botânicas. Como resultado, concluiu-se que as espécies acondicionadas em tubetão obtiveram menores porcentagens de mortalidade, seguidas pelo tubetinho e bandeja. Algumas espécies produzidas em bandeja mostraram índices de mortalidade menores, se comparadas às em tubetinhos, apresentando possibilidades de uso, com manejos que garantam o aumento da sobrevivência inicial das mudas. O hidrogel não interferiu no estabelecimento e crescimento das mudas nos diferentes recipientes. Sobre desenvolvimento em crescimento e incremento em altura, concluiu-se que, garantido o estabelecimento das mudas, não houve diferenças entre recipientes, reforçando que manejos diferenciados poderão reduzir custos na restauração, em situações que exijam plantio total.

Palavras-chave: diversidade, mortalidade de mudas, restauração de áreas degradadas, taxa de sobrevivência

\section{Introdução}

Nos últimos anos, o acúmulo de conhecimento sobre os processos envolvidos na dinâmica de formações naturais, quer sejam preservadas, ou em diferentes graus de degradação, tem levado a mudanças na orientação dos programas de restauração ecológica. Esses programas que começam a assumir a difícil tarefa de reconstrução dos processos ecológicos, portanto das complexas interações presentes nos ecossistemas, de forma a garantir a perpetuação e sustentabilidade da floresta ao longo do tempo, deixando de ser meramente uma aplicação de práticas agronômicas ou silviculturais de plantios de espécies perenes, objetivando apenas a reintrodução de espécies arbóreas numa dada área (Rodrigues \& Gandolfi 2004).

Na implantação de sistemas florestais, é importante que o recipiente e as práticas de plantio garantam boas condições de desenvolvimento do sistema radicular e boa arquitetura das plantas, além de uma maior facilidade no plantio, procurando-se evitar distúrbios

1. Parte da Dissertação de Mestrado do primeiro Autor

2. Universidade de São Paulo, Escola Superior de Agricultura "Luiz de Queiroz", Programa de Pós-graduação em Recurso Florestais, Pádua Dias, 11, Caixa-postal 09, 13418-900 Piracicaba, SP, Brasil

3. Universidade de São Paulo, Escola Superior de Agricultura "Luiz de Queiroz", Departamento de Ciências Florestais, Av. Pádua Dias, 11, Caixa-postal 09, 13418-900 Piracicaba, SP, Brasil

4. Autor para correspondência: barbosa_tiago@yahoo.com.br 
que poderão afetar diretamente o crescimento inicial e a sobrevivência das mudas (Gomes et al. 2003). Nas formações naturais, as plântulas são fundamentais para a manutenção das populações de espécies arbustivas e arbóreas. Em regiões tropicais, as plântulas normalmente apresentam-se em grande número de espécies e indivíduos no sub-bosque de florestas, tanto nativas como algumas exóticas (Viani \& Rodrigues 2008).

O plantio de mudas visando à restauração florestal tem sido bastante usado nos últimos anos, sobretudo em áreas isoladas na paisagem, o que exige, entre outros aspectos, a necessidade de se conhecer os processos determinantes da dinâmica e da manutenção das florestas (Nave \& Rodrigues 2007), além de aprimorar as técnicas para produção de mudas, objetivando a facilitação do seu plantio e a redução de custos, e melhor estabelecimento das mudas nas áreas de restauração.

O conhecimento sobre o desenvolvimento das mudas em diferentes recipientes (bandeja, tubetinhos e tubetões) são ainda insuficientes, em se tratando de espécies florestais nativas (Spurr \& Barnes 1982), não se encontrando muitos trabalhos publicados nessa área, o que indica a necessidade de mais estudos que viabilizem a utilização dos mesmos, sobretudo no que diz respeito ao estabelecimento de plântulas ou mudas arbóreas nativas em campo. De acordo com a procedência das mudas e o recipiente utilizado, podem-se obter resultados diferentes, inclusive em relação àqueles mais utilizados atualmente (tubetes com $56 \mathrm{~cm}^{3}$ ), que é um dos objetivos deste trabalho.

$\mathrm{Na}$ prática, tem-se observado que a utilização de mudas provenientes de recipientes com diferentes tamanhos, em reflorestamentos com espécies nativas visando à restauração ecológica, pode aperfeiçoar os custos não só de produção de mudas, mas também em diversas outras etapas das atividades envolvendo restauração ecológica.

Assim, estudar esses diferentes tipos e tamanhos de recipientes, a fim de verificar aqueles que podem promover maior sucesso ao final dos processos de restauração em áreas degradadas, é uma necessidade e possibilita novas alternativas, tanto para quem exerce essa atividade no campo, quanto para os viveiristas que suprem essa cadeia. Nessa tentativa de otimização do processo, devemos incluir o custo do transporte das mudas, que está diretamente relacionado com o tipo de recipiente usado na produção destas. Mais que isso, aperfeiçoar técnicas de produção que permitam a otimização das práticas de restauração, como as propostas neste trabalho, certamente contribuirão para a melhoria dos métodos e processos de restauração pretendidos.

Outro aspecto importante na implantação dos reflorestamentos é a restrição da época de plantio às épocas chuvosas, ou plantios que fiquem suscetíveis à estiagem, mesmo em épocas de chuva, os chamados veranicos (Vale et al. 2006). Uma alternativa para essas situações é a utilização dos hidrogéis, como condicionadores de umidade no solo. Trata-se de um polímero hidrorretentor, a base de poliacrilato de potássio, que auxilia principalmente na retenção e disponibilidade de água para as plântulas e mudas recém-plantadas (Azevedo 2000).

O objetivo deste trabalho foi avaliar se o tamanho do recipiente utilizado na produção de 30 espécies arbóreas nativas exerce influência no estabelecimento e crescimento de juvenis, com e sem a utilização de hidrogel no plantio.

\section{Material e Métodos}

Aárea de estudo está localizada no Parque Natural Municipal Varginha, que fica no extremo sul do município de São Paulo, SP, no bairro do Varginha, a $30 \mathrm{~km}$ da região central da capital paulista. O Parque está inserido na Bacia Hidrográfica do Alto Tietê, estando a área do presente trabalho sob as coordenadas geográficas $23^{\circ} 47^{\prime} 34,5^{\prime \prime} \mathrm{S}$ e $46^{\circ} 40^{\prime} 19,8^{\prime \prime} \mathrm{W}$, com altitude média de $787 \mathrm{~m}$.

A Bacia Hidrográfica do Alto Tietê abrange área de drenagem que compreende $5.720 \mathrm{~km}^{2}$, incluindo a bacia integral do rio Pinheiros com as sub- bacias dos reservatórios Billings e Guarapiranga (FUSP 2009). A vegetação ocorrente está inserida no bioma Mata Atlântica, apresentando alta biodiversidade.

Segundo a classificação de Köeppen, na região de Parelheiros, São Paulo, SP, ocorrem os tipos climáticos Cfa e Af (Sparovek et al. 2007). O primeiro é caracterizado como úmido, com boa distribuição de chuvas durante o ano, não havendo estação seca bem definida, e temperatura média do ar, no mês mais quente, superior a $22^{\circ} \mathrm{C}$. O segundo apresenta temperatura média do ar entre 24 e $27^{\circ} \mathrm{C}$, com média mensal sempre superior a $18{ }^{\circ} \mathrm{C}$ e com alta pluviosidade (precipitação total anual superior a $2.000 \mathrm{~mm}$ e precipitação média mensal superior a $60 \mathrm{~mm}$, em todos os meses do ano).

A geologia do local caracteriza-se por apresentar sedimentos terciários da bacia de São Paulo, composta 
por conglomerados, areias, argilas e lamitos com espessuras variáveis (Atlas Ambiental do Município de São Paulo 2002). O solo da área apresenta horizonte B latossólico, textura argilosa (42\%), caracterizado como Latossolo Vermelho Amarelo distrófico.

O período de estudos no campo ocorreu durante 12 meses, abrangendo área total de experimento de 1,44 ha. $\mathrm{O}$ delineamento experimental foi realizado em blocos casualizados (DBC), em esquema fatorial $2 \times 3$ (hidrogel $\times$ recipientes), onde cada um dos 5 blocos recebeu os seis tratamentos, ou seja, foram realizadas cinco repetições.

Os tratamentos foram constituídos por combinações do plantio das 30 espécies, provenientes de três diferentes tipos de recipientes, conforme descrito a seguir:

- Bandeja com 288 células, com medida de boca igual a $20 \mathrm{~mm}$, profundidade de $40 \mathrm{~mm}$, volume de $9 \mathrm{~cm}^{3}$, com quatro estrias na parede do recipiente e expedida a campo 80 dias pós semeadura;

- Tubetinho com medida de boca de $30 \mathrm{~mm}$, profundidade de $125 \mathrm{~mm}$, volume de $56 \mathrm{~cm}^{3}$, com seis estrias na parede do recipiente e expedido a campo 150 dias pós semeadura; e

- Tubetão com medida de boca de $50 \mathrm{~mm}$, profundidade de $190 \mathrm{~mm}$, volume de $290 \mathrm{~cm}^{3}$, com oito estrias na parede do recipiente e expedido a campo 180 dias pós semeadura.

A composição do substrato utilizado em todos os recipientes foi sempre a mesma, consistindo de $50 \%$ de fibra de coco, $35 \%$ de casca de arroz carbonizada, $15 \%$ vermiculita super fina, e $2 \mathrm{~kg} \mathrm{~m}^{-3}$ da fórmula NPK 15-09-12 de osmocote.

As plantas provenientes desses recipientes tiveram tratamentos com e sem a utilização do hidrogel (HYDROPLAN-EB/HYB).

As parcelas amostrais foram compostas por 120 plantas $(10 \times 12)$, com espaçamento entre plantas de 2,0 $\times 2,0 \mathrm{~m}$, totalizando $480 \mathrm{~m}^{2}$ por parcela. Em cada parcela foram distribuídas 30 espécies nativas, pertencentes a 17 famílias botânicas, segundo o sistema de classificação "Angiosperm Phylogeny Group" APGII (ANGIOSPERM PHYLOGENY GROUP II, 2003) (tabela 1). Dessa forma, dentro de cada parcela, as plantas pioneiras (57\%) e não pioneiras (43\%) foram distribuídas de forma sistemática, entretanto, as espécies dentro desses grupos foram distribuídas de forma aleatória.

No preparo do solo foram fornecidos, por cova, $100 \mathrm{~g}$ de calcário, $3 \mathrm{~g}$ de N, $15 \mathrm{~g}$ de $\mathrm{P}, 6 \mathrm{~g}$ de K, $15 \mathrm{~g}$ de $\mathrm{Ca}, 1 \mathrm{~g}$ de $\mathrm{Mg}, 3 \mathrm{~g}$ de $\mathrm{S}, 0,05 \mathrm{~g}$ de $\mathrm{Cu}, 1 \mathrm{~g}$ de $\mathrm{Zn}$, $0,02 \mathrm{~g}$ de $\mathrm{Mn}$ e $0,3 \mathrm{~g}$ de B. Na adubação de cobertura, realizada um mês após a implantação, foram utilizados $17 \mathrm{~g}$ de $\mathrm{N}, 7 \mathrm{~g}$ de $\mathrm{K}, 1 \mathrm{~g}$ de $\mathrm{Mg}, 3 \mathrm{~g}$ de S, 0,3 g de B e aminoácidos.

Para testar as hipóteses deste trabalho, os dados foram submetidos aos testes de normalidade (ShapiroWilk) e homogeneidade de variância (Box-Cox) (Zar 1999). Dada a significância da análise de variância, foi realizado o teste de comparação múltipla (Tukey a 5\% de probabilidade) para comparação das médias. Todas as análises foram processadas utilizando-se o Software SAS 9.2 System for Windowns (SAS Institute 2007).

\section{Resultados e Discussão}

Mortalidade - até o primeiro mês, foram observadas as maiores taxas de mortalidade para os três recipientes, sendo que o recipiente bandeja foi o que apresentou a maior taxa (63,5\%); seguido do tubetinho $(25,1 \%)$, enquanto que o tubetão apresentou $3,8 \%$ de mortalidade, para o mesmo período (tabela 2).

Quanto à mortalidade incrementada nos recipientes bandeja e tubetinho (ca. 15\%), para o intervalo entre o primeiro e sexto mês, não foram encontradas diferenças significativas, contudo ambos diferiram do tubetão, que apresentou menor taxa de mortalidade incrementada $(7,2 \%)$, em relação ao mesmo período.

No intervalo entre o sexto e o décimo segundo mês, verifica-se que as taxas de mortalidade incrementadas da $2^{\mathrm{a}}$ para a $3^{\mathrm{a}}$ avaliação não apresentaram diferenças significativas na comparação entre os três tipos de recipientes.

Ao final dos 12 meses de avaliação, a média geral das mortalidades para cada recipiente apresentou-se significativamente diferente, denotando que o tubetão apresentou a menor porcentagem média de mortalidade, com apenas 14\%, o que é compatível com os resultados obtidos com mudas de várias espécies florestais, onde, em geral, recipientes maiores têm obtido melhores resultados (Gomes et al. 1980, Gomes et al. 1981, 1990).

O período mais crítico para o estabelecimento das mudas de tubetinho foram os seis primeiros meses e, para as mudas de bandeja, o período mais crítico ocorreu principalmente até o primeiro mês.

Conforme relataram Lima et al. (2006), é necessário achar o ponto de equilíbrio entre volume e formato de recipiente, visando à obtenção de mudas de qualidade, mas que também possa otimizar os custos 
de produção. Quando o plantio é realizado com mudas oriundas de recipientes com substrato apresentando características desfavoráveis, como, por exemplo, a reduzida capacidade de retenção hídrica, se comparado ao solo usado na produção de mudas em sacolas plásticas, a necessidade de realização de irrigação logo após o plantio, para acomodação do sistema radicular e disponibilização de água no solo, é fundamental; tal como ocorre em viveiros, onde a frequência necessária de irrigação e o volume de água, a ser aplicado em substratos com menor capacidade de retenção de água (casca de arroz carbonizada, areia, moinha de carvão, etc.), deve ser maior e mais frequente do que naqueles de maior capacidade de retenção (terra de subsolo, composto orgânico, húmus, fibra de coco, etc.) (Wendling \& Gatto 2002). O substrato destina-se a sustentar as plantas durante o enraizamento e serve de fonte de nutrientes para as plantas, devendo tratar-se de meio ideal, com porosidade suficiente para proporcionar aeração adequada, que apresente boa

Tabela 1. Listagem das espécies utilizadas na área de plantio, por classes sucessionais. NP: não pioneira; P: pioneira (Barbosa \& Martins 2003, Catharino et al. 2006). * Espécies sobre as quais há controvérsias quanto à regionalidade.

Table 1. List of species used in planting area, by successional classes. NP: non-pioneer; P: pioneer (Barbosa \& Martins 2003, Catharino et al. 2006). * Species which there is controversy regarding their regionality.

\begin{tabular}{|c|c|c|c|}
\hline $\mathrm{CS}$ & Família & Nome Científico & Nome Popular \\
\hline $\mathrm{P}$ & Anacardiaceae & Schinus terebinthifolius Raddi & aroeira-pimenteira \\
\hline $\mathrm{P}$ & Boraginaceae & Cordia superba Cham. & babosa-branca \\
\hline NP & Malvaceae & Luehea grandiflora Mart. \& Zucc. & açoita-cavalo-graúda \\
\hline NP & Bignoniaceae & Handroanthus chrysotrichus (Mart. ex DC.) Mattos & ipê-amarelo-cascudo \\
\hline NP & Moraceae & Maclura tinctoria (L.) D. Don ex Steud. & taiúva \\
\hline$P$ & Verbenaceae & Aloysia virgata (Ruiz \& Pav.) Juss. & lixeira \\
\hline $\mathrm{P}$ & Fabaceae-caesalpinoideae & $\begin{array}{l}\text { Senna macranthera (DC. ex Collad.) H.S.Irwin } \\
\text { \& Barneby }\end{array}$ & manduirana \\
\hline NP & Lythraceae & Lafoensia pacari A.St.-Hil. & dedaleiro \\
\hline NP & Bignoniaceae & Handroanthus vellosoi (Toledo) Mattos & ipê-amarelo-liso \\
\hline NP & Bignoniaceae & Jacaranda cuspidifolia Mart. * & jacarandá-branco \\
\hline$P$ & Euphorbiaceae & Alchornea glandulosa Poepp. \& Endl. & tapiá \\
\hline $\mathrm{P}$ & Rutaceae & Dictyoloma vandellianum A. Juss. & tingui \\
\hline NP & Meliaceae & Cedrela odorata L. & cedro-do-brejo \\
\hline NP & Bignoniaceae & Handroanthus impetiginosus Mattos & ipê-roxo \\
\hline NP & Phytolaccaceae & Gallesia integrifolia (Spreng.) Harms & pau-d'alho \\
\hline $\mathrm{P}$ & Fabaceae-caesalpinoideae & Peltophorum dubium (Spreng.) Taub. & canafístula \\
\hline $\mathrm{P}$ & Euphorbiaceae & Croton floribundus Spreng. & capixingui \\
\hline NP & Rutaceae & Esenbeckia leiocarpa Engl. & guarantã \\
\hline NP & Fabaceae-mimosoideae & Parapiptadenia rigida (Benth.) Brenan & guarucaia \\
\hline NP & Anacardiaceae & Astronium graveolens Jacq. & guarita \\
\hline $\mathrm{P}$ & Myrtaceae & Psidium guajava L. * & goiaba \\
\hline $\mathrm{P}$ & Verbenaceae & Citharexylum myrianthum Cham. & pau-viola \\
\hline NP & Rutaceae & Esenbeckia febrifuga (A.St.-Hil.) A. Juss. ex Mart. & crumarim \\
\hline NP & Bignoniaceae & Handroanthus ochraceus (Cham.) Mattos & ipê-amarelo \\
\hline NP & Bignoniaceae & Tabebuia roseoalba (Ridl.) Sandwith * & ipê-branco \\
\hline $\mathrm{P}$ & Lamiaceae & Aegiphila integrifolia (Jacq.) Moldenke & tamanqueiro \\
\hline $\mathrm{P}$ & Fabaceae-mimosoideae & Senegalia polyphylla (DC.) Britton \& Rose & monjoleiro \\
\hline NP & Meliaceae & Cedrela fissilis Vell. & cedro-rosa \\
\hline NP & Rhamnaceae & Colubrina glandulosa Perkins & sobrasil \\
\hline $\mathrm{P}$ & Apocynaceae & Tabernaemontana laeta Mart. & leiteiro \\
\hline
\end{tabular}


drenagem e tenha capacidade de retenção de líquido satisfatória, para oferecer umidade adequada às mudas (Hartmann \& Kester 2002).

Como essa irrigação inicial não foi realizada pode-se atribuir a esse fato a causa da alta mortalidade apresentada pelas mudas até o $1^{\circ}$ mês após o plantio, constatando-se a drástica redução da mortalidade para bandeja e para tubetinho, após o primeiro mês, o que também ocorreu no tubetão, mas em proporções menores (tabela 2). A mortalidade pode ter sido ainda influenciada pela falta de controle diferenciado de gramíneas agressivas nos primeiros meses após o plantio, nesses diferentes recipientes, já que a muda oriunda da bandeja tem altura muito menor $(10 \mathrm{~cm})$ que a muda oriunda do tubetinho $(20 \mathrm{~cm})$, que por sua vez é menor que a muda do tubetão $(30 \mathrm{~cm}$ ou mais). Apesar do cuidado tomado com as manutenções no período pós-implantação do experimento, essas podem ter sido insuficientes para as mudas menores. A presença de gramíneas agressivas pode ter sido uma das causas que afetou negativamente as mudas de bandeja, juntamente com a falta de irrigação, sendo que, se essas atividades tivessem sido planejadas com frequência distinta para cada tipo de recipiente, certamente a sobrevivência das mudas recém-plantadas seria maior, principalmente nos recipientes de menor volume (bandeja e tubetinho).

As mudas oriundas do recipiente tubetão obtiveram as menores porcentagens de mortalidade (figuras 1, 2 e 3), seguidas de tubetinho e bandeja; sendo que a porcentagem de mortalidade apresentada para o recipiente bandeja variou entre $42,5 \%$, para aroeira-pimenteira (Schinus terebinthifolius) e 100\% para leiteiro (Tabernaemontana laeta) (figura 1). Para o recipiente tubetinho, a variação foi entre $87,5 \%$ para o pau-d'alho (Gallesia integrifolia) e 2,5\% para aroeira-pimenteira (figura 2). Já para os tubetões, a porcentagem média de mortalidade foi entre 37,5\% para manduirana (Senna macranthera), e $0 \%$ para aroeira-pimenteira e lixeira (Aloysia virgata) (figura 3). Entretanto, algumas espécies de bandeja mostraram índices de mortalidade menores, se comparadas a outras espécies provenientes de tubetinhos.

Dada a possibilidade de redução de custos ao utilizar-se a bandeja, poder-se-ia optar por este recipiente para a produção de plantas de algumas espécies que apresentaram melhor pegamento, tais como Schinus terebinthifolius, Peltophorum dubium, Psidium guajava e Citharexylum myrianthum. Ainda assim, é preciso ponderar os dados aqui expostos, pois estes estão considerando apenas a taxa de sobrevivência das plantas e o custo de aquisição, não contabilizando custos de transporte, bem como eventuais custos de replantio aos qual a atividade está sujeita.

Verifica-se um cálculo simples de custos com cada um dos tipos de muda por hectare, considerando plantios em espaçamento $2,0 \times 2,0 \mathrm{~m}$, com 2.500 mudas ha $^{-1}$ (tabela 3).

Os valores não despendidos pela diferença entre os investimentos, com a opção por bandeja ou tubetinho, poderiam ser destinados à tentativa de garantir o aumento da sobrevivência das mudas nos primeiros meses após o plantio, por meio de manutenções diferenciadas, como irrigação e mesmo o controle mais acurado de gramíneas competidoras. Por exemplo, quando se faz a opção pelo recipiente bandeja e assumem-se os riscos quanto ao pegamento das mudas, ao se realizar o cálculo de custo/benefício, para que a opção valha a pena, o valor gasto com reposição de mudas, ou mesmo manutenções diferenciadas, não poderiam ultrapassar a diferença de preço em relação ao tubetinho $(\mathrm{R} \$ 850,00)$ ou tubetão (R\$ 2.400,00). Contudo, para este trabalho, sem promover a irrigação pós-plantio e sem considerar

Tabela 2. Taxa de mortalidade e incremento de mortalidade (\%) de mudas de 30 espécies arbóreas nativas, para três recipientes, em três avaliações.

Table 2. Mortality rate and increased mortality (\%) of 30 seedlings of native tree species, in three types of containers, under three evaluations.

\begin{tabular}{lcccc}
\hline Recipiente & Mortalidade no $1^{\circ}$ mês & $\begin{array}{c}\text { Incremento de mortalidade } \\
1^{\circ} \text { ao } 6^{\circ} \text { mês }\end{array}$ & $\begin{array}{c}\text { Incremento de mortalidade } \\
6^{\circ} \text { ao } 12^{\circ} \text { mês }\end{array}$ & $\begin{array}{c}\text { Mortalidade total no } \\
12^{\circ} \text { mês }\end{array}$ \\
\hline Bandeja & $63,5 \mathrm{a}$ & $15,6 \mathrm{a}$ & $2,6 \mathrm{a}$ & $81,7 \mathrm{a}$ \\
Tubetinho & $25,1 \mathrm{~b}$ & $16,1 \mathrm{a}$ & $2,7 \mathrm{a}$ & $43,9 \mathrm{~b}$ \\
Tubetão & $3,8 \mathrm{c}$ & $7,2 \mathrm{~b}$ & $3,0 \mathrm{a}$ & $14,0 \mathrm{c}$ \\
\hline
\end{tabular}

*Médias seguidas das mesmas letras na vertical não diferem significativamente pelo teste de Tukey a $5 \%$. 


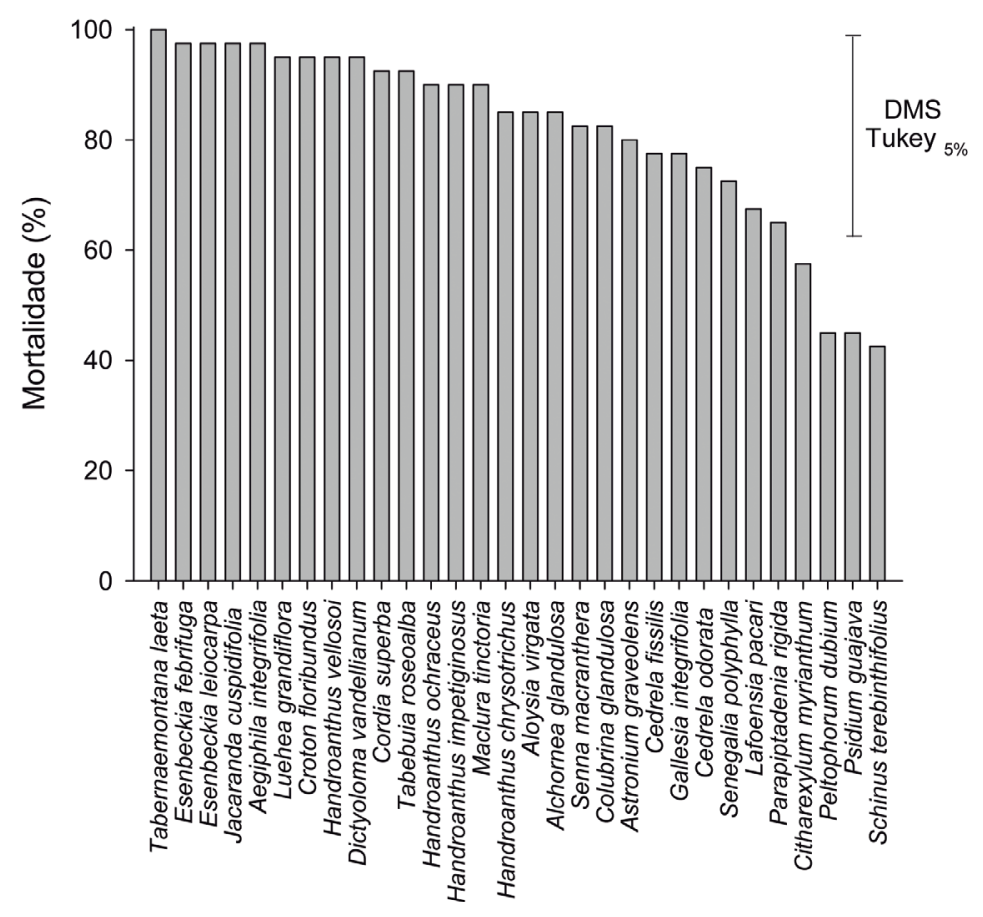

Figura 1. Porcentagem média de mortalidade de 30 espécies arbóreas nativas, com mudas oriundas do recipiente bandeja, 12 meses após o plantio. DMS (Tukey 5\%) = 32,4\%.

Figure 1 . Mortality rate of 30 native species, produced by seedlings from the container bandeja, 12 months after planting. LSD (Tukey $5 \%)=32.4 \%$.

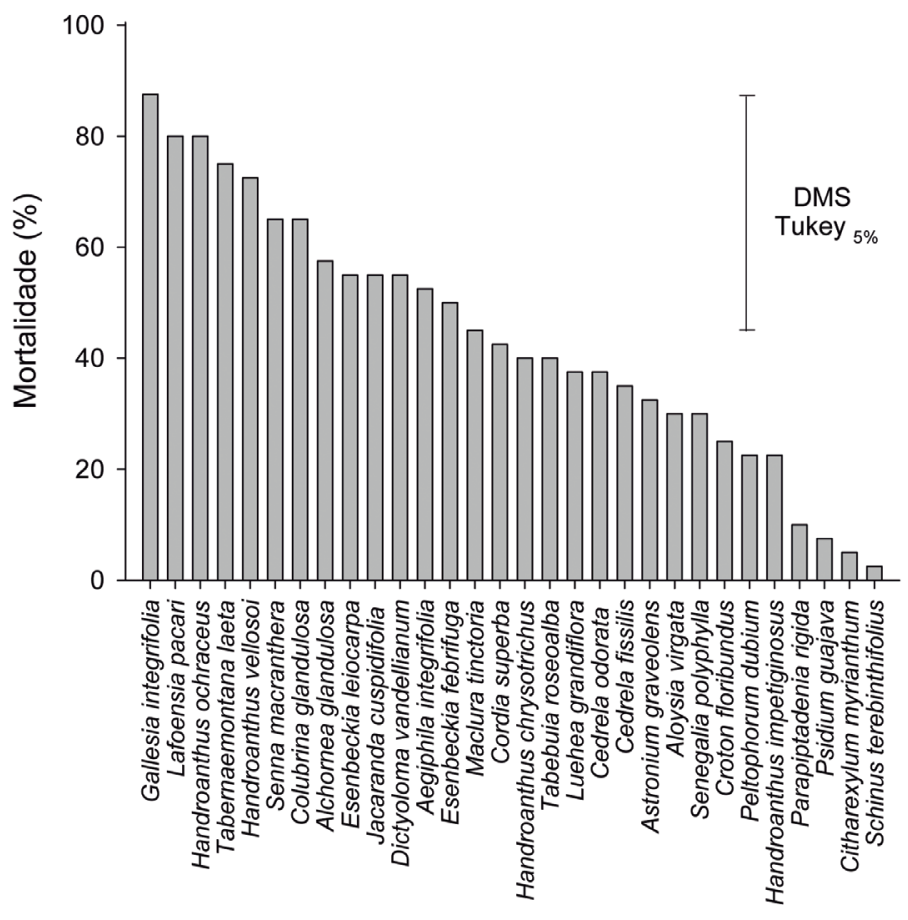

Figura 2. Porcentagem média de mortalidade de 30 espécies arbóreas nativas, com mudas oriundas do recipiente tubetinho, 12 meses após o plantio. DMS(Tukey 5\%) =37,8\%.

Figure 2. Mortality rate of 30 native species, produced by seedlings from the container tubetinho, 12 months after planting. LSD (Tukey $5 \%)=37.8 \%$. 
o custo, o tubetão foi a melhor opção por apresentar os melhores índices de sobrevivência, o que se deve ao recipiente possuir maior volume de substrato (Vianna 1964, Godoy Júnior 1965, Silveira et al. 1973, Besagoitia 1980). Em outras comparações realizadas, confrontando os dados com a literatura disponível, constata-se que tanto o tipo de recipiente, como suas dimensões interferem na qualidade de mudas de espécies florestais, refletindo na sobrevivência inicial das mudas no campo (Carneiro 1987, Souza 1995).

Respostas obtidas para o fator mortalidade, referente às espécies estudadas, estão apresentadas na tabela 4. Dessa forma, é interessante observar como a falta de água e a falta de controle adequado de competidor, na fase inicial, podem ter diferentes efeitos para as espécies. Isso reforça a importância do uso de diversidade em projetos de restauração ecológica, que necessitem utilizar como metodologia o plantio total, conforme defendido por Brancalion et al. (2010).

Hidrogel - avaliando as 30 espécies arbóreas nativas testadas neste projeto e suas interações com o uso de hidrogel pode-se concluir que essa substância hidrorretentora não diminuiu a mortalidade das mudas no campo em nenhuma das avaliações realizadas, não havendo diferença para os resultados obtidos entre tratamentos que receberam e os que não receberam o hidrogel, no momento do plantio das mudas no campo (tabela 5).

Quando comparado o uso de diferentes recipientes para plantios com e sem o uso do hidrogel, não se observou diferenças para a mortalidade das 30 espécies arbóreas nativas testadas (tabela 6).

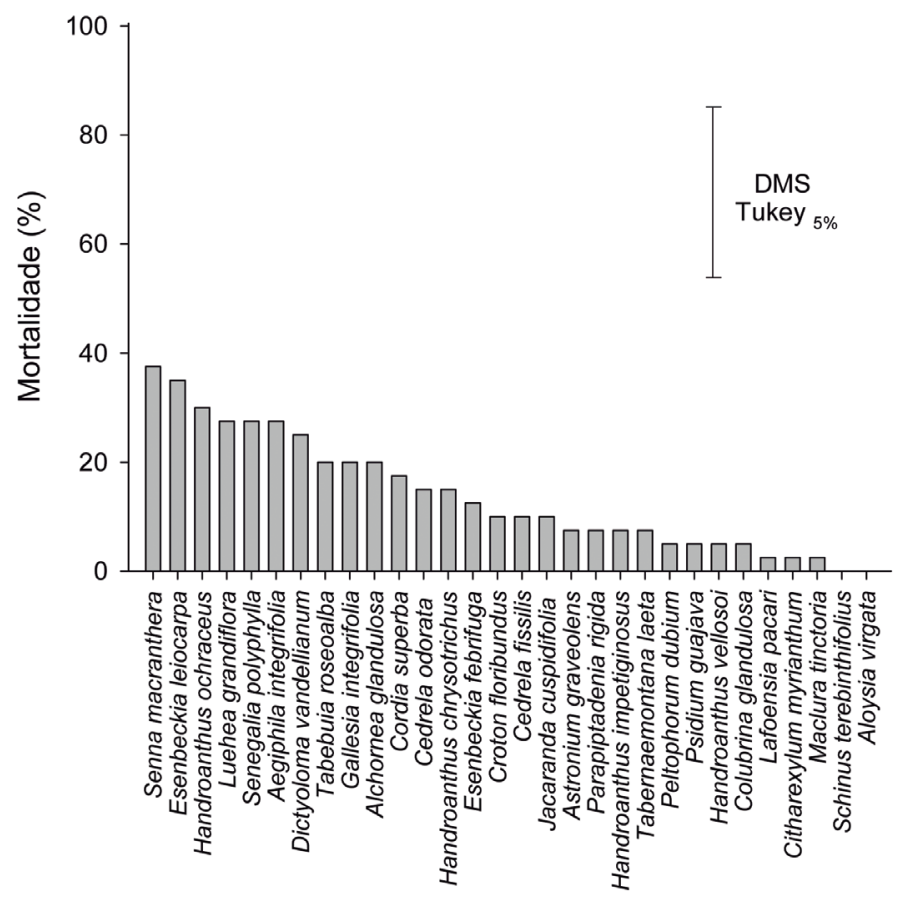

Figura 3. Porcentagem média de mortalidade de 30 espécies arbóreas nativas, com mudas oriundas do recipiente tubetão, 12 meses após o plantio. DMS (Tukey $5 \%$ ) $=27,8 \%$.

Figure 3. Mortality rate of 30 native species, produced by seedlings from the container tubetão, 12 months after planting. LSD (Tukey $5 \%$ ) $=27.8 \%$.

Tabela 3. Custos do insumo por muda por hectare, para cada recipiente (2.500 ha-1 , preço médio de três viveiros em junho/2011).

Table 3. Costs of inputs by seedlings per hectare, for each container (2,500 ha-1, average .price in three nurseries in June/2011).

\begin{tabular}{ccc}
\hline Recipiente & ${\text { Custos } \text { muda }^{-1}(\mathrm{R} \$)}$ & Custo ha $^{-1}(\mathrm{R} \$)$ \\
\hline Bandeja & 0,31 & 775,00 \\
Tubetinho & 0,65 & $1,625,00$ \\
Tubetão & 1,27 & $3.175,00$ \\
\hline
\end{tabular}


Tabela 4. Mortalidade inicial ( 1 mês), \% de mortalidade do $1^{\circ}$ ao $6^{\circ}$ mês e do $6^{\circ}$ ao $12^{\circ}$ mês, e $\%$ de mortalidade ao final (12 meses) de 30 espécies arbóreas nativas, em diferentes recipientes.

Table 4 . Initial mortality ( 1 month), $\%$ of mortality from the $1^{\text {st }}$ to the $6^{\text {th }}$ month and from the $6^{\text {th }}$ to the $12^{\text {th }}$ month, and $\%$ of mortality at the end of the study (12 months) of 30 native species in three different containers.

\begin{tabular}{|c|c|c|c|c|}
\hline Recipientes & $\begin{array}{l}\text { Mortalidade no } \\
1^{\circ} \text { mês }\end{array}$ & $\begin{array}{l}\text { Incremento de mortalidade } \\
\qquad 1^{\circ} \text { ao } 6^{\circ} \text { mês }\end{array}$ & $\begin{array}{l}\text { Incremento de mortalidade } \\
6^{\circ} \text { ao } 12^{\circ} \text { mês }\end{array}$ & $\begin{array}{l}\text { Mortalidade total } \\
\text { no } 12^{\circ} \text { mês }\end{array}$ \\
\hline \multicolumn{5}{|c|}{ Handroanthus ochraceus (Cham.) Mattos - ipê-amarelo } \\
\hline bandeja & $70,0 \mathrm{a}$ & $20,0 \mathrm{a}$ & $0 \mathrm{a}$ & $90,0 \mathrm{a}$ \\
\hline tubetinho & $62,5 \mathrm{a}$ & $12,5 \mathrm{a}$ & $5,0 \mathrm{a}$ & $80,0 \mathrm{a}$ \\
\hline tubetão & $7,5 \mathrm{~b}$ & $20,0 \mathrm{a}$ & $2,5 \mathrm{a}$ & $30,0 \mathrm{~b}$ \\
\hline \multicolumn{5}{|c|}{ Esenbeckia leiocarpa Engl. - guarantã } \\
\hline bandeja & $60,0 \mathrm{a}$ & $35,0 \mathrm{a}$ & $2,5 \mathrm{a}$ & $97,5 \mathrm{a}$ \\
\hline tubetinho & $22,5 \mathrm{~b}$ & $27,5 \mathrm{a}$ & $5,0 \mathrm{a}$ & $55,0 \mathrm{~b}$ \\
\hline tubetão & $5,0 \mathrm{~b}$ & $17,5 \mathrm{a}$ & $12,5 \mathrm{a}$ & $35,0 \mathrm{c}$ \\
\hline \multicolumn{5}{|c|}{ Gallesia integrifolia (Spreng.) Harms - pau-d'alho } \\
\hline bandeja & $27,5 \mathrm{~b}$ & $42,5 \mathrm{a}$ & $7,5 \mathrm{a}$ & $77,5 \mathrm{a}$ \\
\hline tubetinho & $55,0 \mathrm{a}$ & $32,5 \mathrm{ab}$ & $0 \mathrm{a}$ & $87,5 \mathrm{a}$ \\
\hline tubetão & $0 \mathrm{c}$ & $12,5 \mathrm{~b}$ & $7,5 \mathrm{a}$ & $20,0 \mathrm{~b}$ \\
\hline \multicolumn{5}{|c|}{ Senna macranthera (DC. ex Collad.) H.S.Irwin \& Barneby - manduirana } \\
\hline bandeja & $57,5 \mathrm{a}$ & $20,0 \mathrm{a}$ & $5,0 \mathrm{a}$ & $82,5 \mathrm{a}$ \\
\hline tubetinho & $22,5 \mathrm{~b}$ & $32,5 \mathrm{a}$ & $10,0 \mathrm{a}$ & $65,0 \mathrm{a}$ \\
\hline tubetão & $15,0 \mathrm{~b}$ & $12,5 \mathrm{a}$ & $10,0 \mathrm{a}$ & $37,5 \mathrm{~b}$ \\
\hline \multicolumn{5}{|c|}{ Tabernaemontana laeta Mart.- leiteiro } \\
\hline bandeja & $90,0 \mathrm{a}$ & $7,5 \mathrm{~b}$ & $2,5 \mathrm{a}$ & $100,0 \mathrm{a}$ \\
\hline tubetinho & $32,5 \mathrm{~b}$ & $37,5 \mathrm{a}$ & $5,0 \mathrm{a}$ & $75,0 \mathrm{~b}$ \\
\hline tubetão & $0 \mathrm{c}$ & $5,0 \mathrm{~b}$ & $2,5 \mathrm{a}$ & $7,5 \mathrm{c}$ \\
\hline \multicolumn{5}{|c|}{ Aegiphila integrifolia (Jacq.) Moldenke - tamanqueiro } \\
\hline bandeja & $85,0 \mathrm{a}$ & $10,0 \mathrm{a}$ & $2,5 \mathrm{a}$ & $97,5 \mathrm{a}$ \\
\hline tubetinho & $22,5 \mathrm{~b}$ & $25,0 \mathrm{a}$ & $5,0 \mathrm{a}$ & $52,5 \mathrm{~b}$ \\
\hline tubetão & $10,0 \mathrm{~b}$ & $12,5 \mathrm{a}$ & $5,0 \mathrm{a}$ & $27,5 \mathrm{c}$ \\
\hline \multicolumn{5}{|c|}{ Dictyoloma vandellianum A. Juss. - tingui } \\
\hline bandeja & $70,0 \mathrm{a}$ & $20,0 \mathrm{ab}$ & $5,0 \mathrm{a}$ & $95,0 \mathrm{a}$ \\
\hline tubetinho & $15,0 \mathrm{~b}$ & $25,0 \mathrm{a}$ & $15,0 \mathrm{a}$ & $55,0 \mathrm{~b}$ \\
\hline tubetão & $2,5 \mathrm{~b}$ & $5,0 \mathrm{~b}$ & $17,5 \mathrm{a}$ & $25,0 \mathrm{c}$ \\
\hline \multicolumn{5}{|c|}{ Handroanthus vellosoi (Toledo) Mattos - ipê-amarelo-liso } \\
\hline bandeja & $90,0 \mathrm{a}$ & $5,0 \mathrm{ab}$ & $0 \mathrm{a}$ & $95,0 \mathrm{a}$ \\
\hline tubetinho & $42,5 \mathrm{~b}$ & $22,5 \mathrm{a}$ & $7,5 \mathrm{a}$ & $72,5 \mathrm{~b}$ \\
\hline tubetão & $2,5 \mathrm{c}$ & $2,5 \mathrm{~b}$ & $0 \mathrm{a}$ & $5,0 \mathrm{c}$ \\
\hline \multicolumn{5}{|c|}{ Alchornea glandulosa Poepp. \& Endl. - tapiá } \\
\hline bandeja & $75,0 \mathrm{a}$ & $7,5 \mathrm{a}$ & $2,5 \mathrm{a}$ & $85,0 \mathrm{a}$ \\
\hline tubetinho & $32,5 \mathrm{~b}$ & $25,0 \mathrm{a}$ & $0 \mathrm{a}$ & $57,5 \mathrm{~b}$ \\
\hline tubetão & $5,0 \mathrm{c}$ & $12,5 \mathrm{a}$ & $2,5 \mathrm{a}$ & $20,0 \mathrm{c}$ \\
\hline
\end{tabular}


Tabela 4 (continuação)

\begin{tabular}{|c|c|c|c|c|}
\hline Recipientes & $\begin{array}{c}\text { Mortalidade no } \\
1^{\circ} \text { mês }\end{array}$ & $\begin{array}{l}\text { Incremento de mortalidade } \\
1^{\circ} \text { ao } 6^{\circ} \text { mês }\end{array}$ & $\begin{array}{l}\text { Incremento de mortalidade } \\
6^{\circ} \text { ao } 12^{\circ} \text { mês }\end{array}$ & $\begin{array}{l}\text { Mortalidade total } \\
\text { no } 12^{\circ} \text { mês }\end{array}$ \\
\hline \multicolumn{5}{|c|}{ Jacaranda cuspidifolia Mart. - jacarandá-branco } \\
\hline bandeja & $85,0 \mathrm{a}$ & $7,5 \mathrm{a}$ & $5,0 \mathrm{a}$ & $97,5 \mathrm{a}$ \\
\hline tubetinho & $42,5 \mathrm{~b}$ & $10,0 \mathrm{a}$ & $2,5 \mathrm{a}$ & $55,0 \mathrm{~b}$ \\
\hline tubetão & $5,0 \mathrm{c}$ & $2,5 \mathrm{a}$ & $2,5 \mathrm{a}$ & $10,0 \mathrm{c}$ \\
\hline \multicolumn{5}{|c|}{ Luehea grandiflora Mart. Et Zucc. - açoita-cavalo-graúda } \\
\hline bandeja & $80,0 \mathrm{a}$ & $10,0 \mathrm{a}$ & $5,0 \mathrm{a}$ & $95,0 \mathrm{a}$ \\
\hline tubetinho & $27,5 \mathrm{~b}$ & $7,5 \mathrm{a}$ & $2,5 \mathrm{a}$ & $37,5 \mathrm{~b}$ \\
\hline tubetão & $7,5 \mathrm{~b}$ & $15,0 \mathrm{a}$ & $5,0 \mathrm{a}$ & $27,5 \mathrm{~b}$ \\
\hline \multicolumn{5}{|c|}{ Esenbeckia febrifuga (A. St.-Hil.) A. Juss. ex Mart. - crumarim } \\
\hline bandeja & $72,5 \mathrm{a}$ & $25,0 \mathrm{a}$ & $0 \mathrm{a}$ & $97,5 \mathrm{a}$ \\
\hline tubetinho & $27,5 \mathrm{~b}$ & $20,0 \mathrm{a}$ & $2,5 \mathrm{a}$ & $50,0 \mathrm{~b}$ \\
\hline tubetão & $5,0 \mathrm{c}$ & $5,0 \mathrm{a}$ & $2,5 \mathrm{a}$ & $12,5 \mathrm{c}$ \\
\hline \multicolumn{5}{|c|}{ Tabebuia roseoalba (Ridl.) Sandwith - ipê-branco } \\
\hline bandeja & $82,5 \mathrm{a}$ & $7,5 \mathrm{a}$ & $2,5 \mathrm{a}$ & $92,5 \mathrm{a}$ \\
\hline tubetinho & $32,5 \mathrm{~b}$ & $12,5 \mathrm{a}$ & $-5,0 \mathrm{a}$ & $40,0 \mathrm{~b}$ \\
\hline tubetão & $7,5 \mathrm{c}$ & $5,0 \mathrm{a}$ & $7,5 \mathrm{a}$ & $20,0 \mathrm{c}$ \\
\hline \multicolumn{5}{|c|}{ Cordia superba Cham. - babosa-branca } \\
\hline bandeja & $80,0 \mathrm{a}$ & $7,5 \mathrm{a}$ & $5,0 \mathrm{a}$ & $92,5 \mathrm{a}$ \\
\hline tubetinho & $32,5 \mathrm{~b}$ & $5,0 \mathrm{a}$ & $5,0 \mathrm{a}$ & $42,5 \mathrm{~b}$ \\
\hline tubetão & $2,5 \mathrm{c}$ & $12,5 \mathrm{a}$ & $2,5 \mathrm{a}$ & $17,5 \mathrm{~b}$ \\
\hline \multicolumn{5}{|c|}{ Colubrina glandulosa Perkins - sobrasil } \\
\hline bandeja & $65,0 \mathrm{a}$ & $17,5 \mathrm{a}$ & $0 \mathrm{~b}$ & $82,5 \mathrm{a}$ \\
\hline tubetinho & $40,0 \mathrm{~b}$ & $12,5 \mathrm{a}$ & $12,5 \mathrm{a}$ & $65,0 \mathrm{a}$ \\
\hline tubetão & $0 \mathrm{c}$ & $5,0 \mathrm{a}$ & $0 \mathrm{~b}$ & $5,0 \mathrm{~b}$ \\
\hline \multicolumn{5}{|c|}{ Lafoensia pacari A.St.-Hil.- dedaleiro } \\
\hline bandeja & $52,5 \mathrm{a}$ & $12,5 \mathrm{a}$ & $2,5 \mathrm{a}$ & $67,5 \mathrm{a}$ \\
\hline tubetinho & $67,5 \mathrm{a}$ & $12,5 \mathrm{a}$ & $0 \mathrm{a}$ & $80,0 \mathrm{a}$ \\
\hline tubetão & $0 \mathrm{~b}$ & $2,5 \mathrm{a}$ & $0 \mathrm{a}$ & $2,5 \mathrm{~b}$ \\
\hline \multicolumn{5}{|c|}{ Handroanthus chrysotrichus (Mart. ex DC.) Mattos - ipê-amarelo-cascudo } \\
\hline bandeja & $72,5 \mathrm{a}$ & $12,5 \mathrm{a}$ & $0 \mathrm{a}$ & $85,0 \mathrm{a}$ \\
\hline tubetinho & $25,0 \mathrm{~b}$ & $15,0 \mathrm{a}$ & $0 \mathrm{a}$ & $40,0 \mathrm{~b}$ \\
\hline tubetão & $10,0 \mathrm{~b}$ & $2,5 \mathrm{a}$ & $2,5 \mathrm{a}$ & $15,0 \mathrm{c}$ \\
\hline \multicolumn{5}{|c|}{ Maclura tinctoria (L.) D. Don ex Steud. - taiúva } \\
\hline bandeja & 85,0 a & $2,5 \mathrm{~b}$ & $2,5 \mathrm{a}$ & $90,0 \mathrm{a}$ \\
\hline tubetinho & $22,5 \mathrm{~b}$ & $25,0 \mathrm{a}$ & $-2,5 \mathrm{a}$ & $45,0 \mathrm{~b}$ \\
\hline tubetão & $0 \mathrm{~b}$ & $2,5 \mathrm{~b}$ & $0 \mathrm{a}$ & $2,5 \mathrm{c}$ \\
\hline \multicolumn{5}{|c|}{ Croton floribundus Spreng. - capixingui } \\
\hline bandeja & $85,0 \mathrm{a}$ & $10,0 \mathrm{a}$ & $0 \mathrm{a}$ & $95,0 \mathrm{a}$ \\
\hline tubetinho & $17,5 \mathrm{~b}$ & $7,5 \mathrm{a}$ & $0 \mathrm{a}$ & $25,0 \mathrm{~b}$ \\
\hline tubetão & $0 \mathrm{c}$ & $7,5 \mathrm{a}$ & $2,5 \mathrm{a}$ & $10,0 \mathrm{~b}$ \\
\hline
\end{tabular}




\section{Tabela 4 (continuação)}

\begin{tabular}{|c|c|c|c|c|}
\hline Recipientes & $\begin{array}{c}\text { Mortalidade no } \\
1^{\circ} \text { mês }\end{array}$ & $\begin{array}{l}\text { Incremento de mortalidade } \\
\qquad 1^{\circ} \text { ao } 6^{\circ} \text { mês }\end{array}$ & $\begin{array}{l}\text { Incremento de mortalidade } \\
6^{\circ} \text { ao } 12^{\circ} \text { mês }\end{array}$ & $\begin{array}{l}\text { Mortalidade total } \\
\text { no } 12^{\circ} \text { mês }\end{array}$ \\
\hline \multicolumn{5}{|c|}{ Senegalia polyphylla (DC.) Britton \& Rose - monjoleiro } \\
\hline bandeja & $45,0 \mathrm{a}$ & $17,5 \mathrm{a}$ & $10,0 \mathrm{a}$ & $72,5 \mathrm{a}$ \\
\hline tubetinho & $20,0 \mathrm{~b}$ & $12,5 \mathrm{a}$ & $-2,5 b$ & $30,0 \mathrm{~b}$ \\
\hline tubetão & $12,5 \mathrm{~b}$ & $15,0 \mathrm{a}$ & $0 \mathrm{ab}$ & $27,5 \mathrm{~b}$ \\
\hline \multicolumn{5}{|c|}{ Cedrela odorata L. - cedro-do-brejo } \\
\hline bandeja & $45,0 \mathrm{a}$ & $25,0 \mathrm{a}$ & $5,0 \mathrm{a}$ & $75,0 \mathrm{a}$ \\
\hline tubetinho & $17,5 \mathrm{~b}$ & $20,0 \mathrm{a}$ & $0 \mathrm{a}$ & $37,5 \mathrm{~b}$ \\
\hline tubetão & $2,5 \mathrm{~b}$ & $12,5 \mathrm{a}$ & $0 \mathrm{a}$ & $15,0 \mathrm{~b}$ \\
\hline \multicolumn{5}{|c|}{ Cedrela fissilis Vell. - cedro-rosa } \\
\hline bandeja & $55,0 \mathrm{a}$ & $20,0 \mathrm{a}$ & $2,5 \mathrm{a}$ & $77,5 \mathrm{a}$ \\
\hline tubetinho & $10,0 \mathrm{~b}$ & $17,5 \mathrm{a}$ & $7,5 \mathrm{a}$ & $35,0 \mathrm{~b}$ \\
\hline tubetão & $2,5 \mathrm{~b}$ & $5,0 \mathrm{a}$ & $2,5 \mathrm{a}$ & $10,0 \mathrm{~b}$ \\
\hline \multicolumn{5}{|c|}{ Astronium graveolens Jacq. - guarita } \\
\hline bandeja & $60,0 \mathrm{a}$ & $25,0 \mathrm{a}$ & $-5,0 \mathrm{a}$ & $80,0 \mathrm{a}$ \\
\hline tubetinho & $17,5 \mathrm{~b}$ & $10,0 \mathrm{ab}$ & $5,0 \mathrm{a}$ & $32,5 \mathrm{~b}$ \\
\hline tubetão & $7,5 \mathrm{~b}$ & $-2,5 b$ & $2,5 \mathrm{a}$ & $7,5 \mathrm{c}$ \\
\hline \multicolumn{5}{|c|}{ Handroanthus impetiginosus Mattos - ipê-roxo } \\
\hline bandeja & $57,5 \mathrm{a}$ & $22,5 \mathrm{a}$ & $10,0 \mathrm{a}$ & $90,0 \mathrm{a}$ \\
\hline tubetinho & $5,0 \mathrm{~b}$ & $17,5 \mathrm{a}$ & $0 \mathrm{a}$ & $22,5 \mathrm{~b}$ \\
\hline tubetão & $0 \mathrm{~b}$ & $7,5 \mathrm{a}$ & $0 \mathrm{a}$ & $7,5 \mathrm{~b}$ \\
\hline \multicolumn{5}{|c|}{ Aloysia virgata (Ruiz \& Pav.) Juss. - lixeira } \\
\hline bandeja & $80,0 \mathrm{a}$ & $2,5 \mathrm{a}$ & $2,5 \mathrm{a}$ & $85,0 \mathrm{a}$ \\
\hline tubetinho & $25,0 \mathrm{~b}$ & $2,5 \mathrm{a}$ & $2,5 \mathrm{a}$ & $30,0 \mathrm{~b}$ \\
\hline tubetão & $0 \mathrm{c}$ & $0 \mathrm{a}$ & $0 \mathrm{a}$ & $0 \mathrm{c}$ \\
\hline \multicolumn{5}{|c|}{ Parapiptadenia rigida (Benth.) Brenan - guarucaia } \\
\hline bandeja & $20,0 \mathrm{a}$ & $42,5 \mathrm{a}$ & $2,5 \mathrm{a}$ & $65,0 \mathrm{a}$ \\
\hline tubetinho & $2,5 \mathrm{~b}$ & $12,5 \mathrm{~b}$ & $-5,0 \mathrm{a}$ & $10,0 \mathrm{~b}$ \\
\hline tubetão & $0 \mathrm{~b}$ & $7,5 \mathrm{~b}$ & $0 \mathrm{a}$ & $7,5 \mathrm{~b}$ \\
\hline \multicolumn{5}{|c|}{ Peltophorum dubium (Spreng.) Taub. - canafístula } \\
\hline bandeja & $25,0 \mathrm{a}$ & $20,0 \mathrm{a}$ & $0 \mathrm{a}$ & $45,0 \mathrm{a}$ \\
\hline tubetinho & $12,5 \mathrm{ab}$ & $7,5 \mathrm{a}$ & $2,5 \mathrm{a}$ & $22,5 \mathrm{ab}$ \\
\hline tubetão & $0 \mathrm{~b}$ & $2,5 \mathrm{a}$ & $2,5 \mathrm{a}$ & $5,0 \mathrm{~b}$ \\
\hline \multicolumn{5}{|c|}{ Citharexylum myrianthum Cham. - pau-viola } \\
\hline bandeja & $45,0 \mathrm{a}$ & $10 \mathrm{a}$ & $2,5 \mathrm{a}$ & $57,5 \mathrm{a}$ \\
\hline tubetinho & $2,5 \mathrm{~b}$ & $2,5 \mathrm{a}$ & $0 \mathrm{a}$ & $5,0 \mathrm{~b}$ \\
\hline tubetão & $2,5 \mathrm{~b}$ & $2,5 \mathrm{a}$ & $-2,5 \mathrm{a}$ & $2,5 \mathrm{~b}$ \\
\hline
\end{tabular}


Tabela 4 (continuação)

\begin{tabular}{|c|c|c|c|c|}
\hline Recipientes & $\begin{array}{l}\text { Mortalidade no } \\
1^{\circ} \text { mês }\end{array}$ & $\begin{array}{l}\text { Incremento de mortalidade } \\
1^{\circ} \text { ao } 6^{\circ} \text { mês }\end{array}$ & $\begin{array}{c}\text { Incremento de mortalidade } \\
6^{\circ} \text { ao } 12^{\circ} \text { mês }\end{array}$ & $\begin{array}{l}\text { Mortalidade total } \\
\text { no } 12^{\circ} \text { mês }\end{array}$ \\
\hline \multicolumn{5}{|c|}{ Psidium guajava L. - goiaba } \\
\hline bandeja & $45,0 \mathrm{a}$ & $0 \mathrm{a}$ & $0 \mathrm{a}$ & $45,0 \mathrm{a}$ \\
\hline tubetinho & $7,5 \mathrm{~b}$ & $2,5 \mathrm{a}$ & $-2,5 \mathrm{a}$ & $7,5 \mathrm{~b}$ \\
\hline tubetão & $0 \mathrm{~b}$ & $5,0 \mathrm{a}$ & $0 \mathrm{a}$ & $5,0 \mathrm{~b}$ \\
\hline \multicolumn{5}{|c|}{ Schinus terebinthifolius Raddi - aroeira-pimenteira } \\
\hline bandeja & $45,0 \mathrm{a}$ & $0 \mathrm{a}$ & $-2,5 \mathrm{a}$ & $42,5 \mathrm{a}$ \\
\hline tubetinho & $7,5 \mathrm{~b}$ & $-5 a$ & $0 \mathrm{a}$ & $2,5 \mathrm{~b}$ \\
\hline tubetão & $0 \mathrm{~b}$ & $0 \mathrm{a}$ & $0 \mathrm{a}$ & $0 \mathrm{~b}$ \\
\hline
\end{tabular}

*Médias seguidas pelas mesmas letras na vertical não diferem significativamente pelo teste de Tukey a 5\%.*

Tabela 5. Porcentual de mortalidade de 30 espécies arbóreas nativas, plantadas com ou sem utilização do hidrogel, em três avaliações.

Table 5. Mortality rate of 30 native tree species in three evaluations, planted with or without use of hydrogel.

\begin{tabular}{cccc}
\hline Hidrogel & 1 mês & 6 meses & 12 meses \\
\hline Com hidrogel & $31,4 \mathrm{a}$ & $13,2 \mathrm{a}$ & $2,6 \mathrm{a}$ \\
Sem hidrogel & $30,2 \mathrm{a}$ & $12,6 \mathrm{a}$ & $2,9 \mathrm{a}$ \\
\hline
\end{tabular}

* Médias seguidas pelas mesmas letras na vertical não diferem significativamente pelo teste de Tukey a 5\%.

Tabela 6. Porcentual de mortalidade de 30 espécies arbóreas nativas, plantadas com ou sem utilização do hidrogel, oriundas de diferentes recipientes.

Table 6. Mortality rate of 30 native tree species from three different containers, planted with or without use of hydrogel.

\begin{tabular}{ccc}
\hline Recipiente & Sem hidrogel & Com hidrogel \\
\hline Bandeja & $24,8 \mathrm{a}$ & $25,0 \mathrm{a}$ \\
Tubetinho & $12,1 \mathrm{a}$ & $12,5 \mathrm{a}$ \\
Tubetão & $2,6 \mathrm{a}$ & $3,7 \mathrm{a}$ \\
\hline
\end{tabular}

* Médias seguidas pelas mesmas letras na horizontal não diferem significativamente pelo teste de Tukey a 5\%.

No que diz respeito à influência do hidrogel no incremento médio em altura a cada avaliação e crescimento médio total (para os três recipientes), envolvendo as 30 espécies arbóreas nativas, nota-se que o hidrogel não interferiu no crescimento dessas mudas ao longo do período de avaliação (12 meses), não tendo sido constatadas diferenças significativas nos tratamentos (tabela 7).

Analisando o incremento médio em altura para um mesmo tipo de recipiente, com e sem hidrogel, também não foram detectadas diferenças significativas (tabela 8).

Assim, com base no que foi apresentado até aqui, conclui-se que o hidrogel não interferiu no estabelecimento ou no crescimento das mudas nos diferentes tratamentos, no período em que o experimento foi avaliado. Os resultados obtidos corroboram com os encontrados por autores que relataram que o uso de hidrogel não influenciou na sobrevivência e nem no crescimento das espécies que estudaram, podendo o uso do hidrogel até ter sido prejudicial em alguns casos (Flannery \& Busscher 1982, Macedo et al. 2003).

Esses resultados contrapõem o que diversos autores encontraram, quando relataram as vantagens com a utilização do hidrogel, como a aceleração do crescimento da parte aérea (Henderson \& Hensley 1986, Lamont \& O'Connell 1987, Vlach 1991). Buzetto et al. (2002) relataram, que o hidrogel foi capaz de promover maior sobrevivência e crescimento de Eucalyptus urophylla.

Cabe aqui uma ressalva, quanto ao fato de que a região onde o experimento foi implantado não apresentou período de deficiência hídrica. Sendo assim, se o experimento fosse implantado em outra região, 
com outro tipo de solo (mais arenoso), ou numa época de maior restrição hídrica nessa mesma região, ou ainda passasse por estresse hídrico temporário, muito provavelmente o hidrogel teria surtido efeito nos resultados de estabelecimento e/ou crescimento das mudas, como sugerido por alguns autores (Vale et al. 2006), ou como encontrado por Nimah et al. (1983), quando observaram diferenças na disponibilidade de água em solos arenosos, garantindo acréscimo de $125 \%$ no fornecimento de água, e em solos argilosos, com $25 \%$ - 30\% de acréscimo com a utilização de hidrogel.

O hidrogel pode ser dispensado tanto em regiões, quanto em épocas do ano sem déficit hídrico, corroborando com o trabalho de Souza et al. (2006) que analisaram o crescimento em campo de espécies de eucalipto e nativas brasileiras, com adição de hidrogel, e não verificaram diferenças entre os tratamentos, justificando tal resultado pelo plantio no período das chuvas.

Incremento em altura - avaliando a média em altura para 30 espécies arbóreas nativas, verificou-se que as mudas produzidas em bandeja apresentavam alturas iniciais de aproximadamente $10 \mathrm{~cm}$, bem inferiores às mudas produzidas em tubetinho e tubetão, que apresentavam, em média, 20 e $30 \mathrm{~cm}$, respectivamente. Isso interferiu fortemente na avaliação inicial, fazendo com que as diferenças fossem significativas para o período dessa avaliação (tabela 9 ). $\mathrm{Na} 2^{\mathrm{a}}$ avaliação (incremento de altura do $1^{\circ}$ ao $6^{\circ}$ mês), as plantas de bandeja, que efetivamente conseguiram se estabelecer, obtiveram médias de incremento semelhantes às plantas de tubetinho e tubetão, não diferindo estatisticamente para esse período. A mesma resposta também foi detectada na $3^{\text {a }}$ avaliação (incremento

Tabela 7. Incremento médio em altura $(\mathrm{cm})$ de mudas de 30 espécies arbóreas nativas, plantadas com ou sem utilização do hidrogel, aos 6 e 12 meses após o plantio.

Table 7. Seedling height increase $(\mathrm{cm})$ of 30 native tree species at 6 and 12 months after planting, planted with or without use of hydrogel.

\begin{tabular}{ccccc}
\hline Hidrogel & $\begin{array}{c}1^{\circ} \text { mês } \\
\text { (inicial) }\end{array}$ & $\begin{array}{c}\text { Incremento } \\
1^{\circ} \text { ao } 6^{\circ} \text { mês }\end{array}$ & $\begin{array}{c}\text { Incremento } \\
6^{\circ} \text { ao } 12^{\circ} \text { meses }\end{array}$ & $12^{\circ}$ mês (final) \\
\hline Com hidrogel & $21,1 \mathrm{a}$ & $15,6 \mathrm{a}$ & $35,6 \mathrm{a}$ & $72,3 \mathrm{a}$ \\
Sem hidrogel & $19,8 \mathrm{a}$ & $18,6 \mathrm{a}$ & $32,8 \mathrm{a}$ & $71,2 \mathrm{a}$ \\
\hline
\end{tabular}

* Médias seguidas pelas mesmas letras na vertical não diferem significativamente pelo teste de Tukey a 5\%.

Tabela 8. Incremento médio em altura $(\mathrm{cm})$ de mudas de 30 espécies arbóreas nativas, plantadas com ou sem utilização do hidrogel, oriundas de diferentes recipientes.

Table 8 . Increase in height $(\mathrm{cm})$ of seedlings of 30 native tree species from different containers, planted with or without use of hydrogel.

\begin{tabular}{ccc}
\hline Recipiente & Sem hidrogel & Com hidrogel \\
\hline Bandeja & $27,9 \mathrm{a}$ & $29,8 \mathrm{a}$ \\
Tubetinho & $40,7 \mathrm{a}$ & $40,7 \mathrm{a}$ \\
Tubetão & $52,3 \mathrm{a}$ & $44,0 \mathrm{a}$ \\
\hline
\end{tabular}

* Médias seguidas pelas mesmas letras na horizontal não diferem significativamente pelo teste de Tukey a 5\%.

Tabela 9. Altura e incremento de altura $(\mathrm{cm})$ de mudas de 30 espécies arbóreas nativas, para três recipientes, em três avaliações. Table 9. Seedling height and height increase $(\mathrm{cm})$ of 30 native tree species, from three containers, in three evaluations.

\begin{tabular}{ccccc}
\hline Recipiente & $\begin{array}{c}\text { Altura no } \\
1^{\circ} \text { mês }\end{array}$ & $\begin{array}{c}\text { Incremento de altura } \\
1^{\circ} \text { ao } 6^{\circ} \text { mês }\end{array}$ & $\begin{array}{c}\text { Incremento de altura } \\
6^{\circ} \text { ao } 12^{\circ} \text { mês }\end{array}$ & Altura total no $12^{\circ}$ mês \\
\hline Bandeja & $12,1 \mathrm{c}$ & $17,1 \mathrm{a}$ & $36,6 \mathrm{a}$ & $65,8 \mathrm{a}$ \\
Tubetinho & $20,4 \mathrm{~b}$ & $17,4 \mathrm{a}$ & $33,3 \mathrm{a}$ & $71,1 \mathrm{a}$ \\
tubetão & $28,9 \mathrm{a}$ & $16,8 \mathrm{a}$ & $32,9 \mathrm{a}$ & $78,6 \mathrm{a}$ \\
\hline
\end{tabular}

*Médias seguidas pelas mesmas letras na vertical não diferem significativamente pelo teste de Tukey a 5\%. 
de altura do $6^{\circ}$ ao $12^{\circ}$ mês). Ao final dos 12 meses, registrou-se que não houve diferenças observadas quanto ao incremento e altura final nos três recipientes estudados, assemelhando-se ao trabalho de Barros et al. (1978), que apresentou dados onde mudas em tubetes pequenos $\left(50 \mathrm{~cm}^{3}\right)$, apesar de terem menor crescimento no viveiro, recuperam no campo o crescimento em altura (tabela 9).

Assim, conclui-se que, uma vez garantido o estabelecimento das mudas, seja qual for o recipiente, as mesmas não apresentaram diferenças entre si quanto ao incremento e crescimento médio em altura; podendo-se pressupor que, com manejos iniciais diferenciados visando ao aumento da sobrevivência de mudas de bandeja, como por exemplo, com irrigação pós-plantio e maior cuidado no controle de gramíneas competidoras nos primeiros meses, os custos da restauração ecológica de uma dada área poderão ser significativamente reduzidos, para situações que exijam como metodologia o plantio total. Ainda assim, é importante adequar as dimensões dos recipientes, uma vez que o uso de recipientes maiores implica em custos que podem ser desnecessários na produção de mudas, conforme descrito por Gomes et al. (1990), na produção de mudas de ipê (Tabebuia serratifolia (Vahl) Nich.), copaíba (Copaifera langsdorffii Desf.) e angico-vermelho (Piptadenia peregrina (L.) Benth.), relatando também a necessidade de se estudar recipientes mais adequados, de acordo com as características de cada espécie e tempo de permanência no viveiro.

As figuras 4, 5 e 6 apresentam a grande heterogeneidade de resposta para o crescimento das espécies no período de 12 meses. A menor altura, ao final do período avaliado, foi obtida pela espécie Tabebuia roseaoalba (ipê-branco), no recipiente bandeja, apresentando o valor de $16,3 \mathrm{~cm}$, e ainda para o mesmo recipiente, a espécie que apresentou a maior altura foi o Citharexylum myrianthum (pau-viola), com 116,9 cm de altura (figura 4).

A maior altura, no recipiente tubetinho, foi observada também para o pau-viola, apresentando o valor de $145,1 \mathrm{~cm}$, e a espécie que menos se desenvolveu nesse recipiente, considerando o período de avaliação do experimento, foi a Esenbeckia leiocarpa (guarantã), apresentando altura de 24,7 cm (figura 5). A maior altura alcançada para os 12 meses contemplados, dentre os três recipientes, foi a Aloysia virgata (lixeira), que em tubetão chegou a $149,4 \mathrm{~cm}$ de altura, sendo a menor altura, para esse mesmo recipiente, também alcançada pelo guarantã, medindo $37,2 \mathrm{~cm}$ (figura 6).

Quanto ao incremento de altura (tabela 10), foi possível verificar que 22 de 30 espécies estudadas não apresentaram diferenças significativas quanto ao incremento de altura, do $1^{\mathrm{a}}$ ao $6^{\mathrm{o}}$ mês e nem do $6^{\circ}$ ao $12^{\circ}$ mês, demonstrando que para essa região, sem déficit hídrico, o crescimento da maioria das espécies pode estar sendo continuado.

Por outro lado, das oito espécies que apresentaram alguma diferença significativa para os incrementos, cinco corresponderam ao período entre o $1^{\circ}$ e o $6^{\circ}$ mês, não apresentando diferença para o período contemplado entre o $6^{\circ}$ ao $12^{\circ}$ mês, e três espécies não apresentaram diferença para o incremento obtido entre o $1^{\circ}$ e o $6^{\circ}$ mês, contudo apresentando diferenças entre o $6^{\circ}$ e o $12^{\circ}$ mês.

As espécies pioneiras $(\mathrm{P})$ apresentaram maiores médias de crescimento absoluto, em relação às espécies não pioneiras (NP) (figura 10). As espécies NP, por fazerem parte de estádios intermediário e final da sucessão natural, normalmente apresentam desenvolvimento mais lento, com menor velocidade de crescimento a pleno sol, se comparado às P. Isso ocorre, pois se trata de adaptação evolutiva de algumas espécies que necessitam ocupar diferentes locais, com condições específicas dentro da floresta, para garantir sua autoperpetuação (Whitmore 1989). As espécies pioneiras, por necessitarem maiores níveis de radiação, condição encontrada por ocasião do plantio, apresentaram maior velocidade de crescimento (Souza \& Valio 2003). Analisando as alturas das espécies pioneiras, depreende-se que só houve diferenças significativas entre o recipiente bandeja em relação aos demais; porém, para as espécies não pioneiras, verifica-se que as espécies oriundas do tubetão apresentaram maior média de altura em relação a bandeja e tubetinho, que não diferiram estatisticamente entre si (figura 7).

Nota-se, contudo, que para ambos os grupos não houve diferença significativa para o incremento obtido do $1^{\circ}$ ao $6^{\circ}$ e do $6^{\circ}$ ao $12^{\circ}$ mês.

Dentre as 30 espécies estudadas, esperava-se maior crescimento das espécies classificadas, como pioneiras, face às não pioneiras (tabela 1 ). Contudo, considerando a média dos dados referente às alturas obtidas para cada espécie nos três recipientes, nove delas obtiveram crescimentos que diferiram do esperado, com base na classificação existente na literatura. 


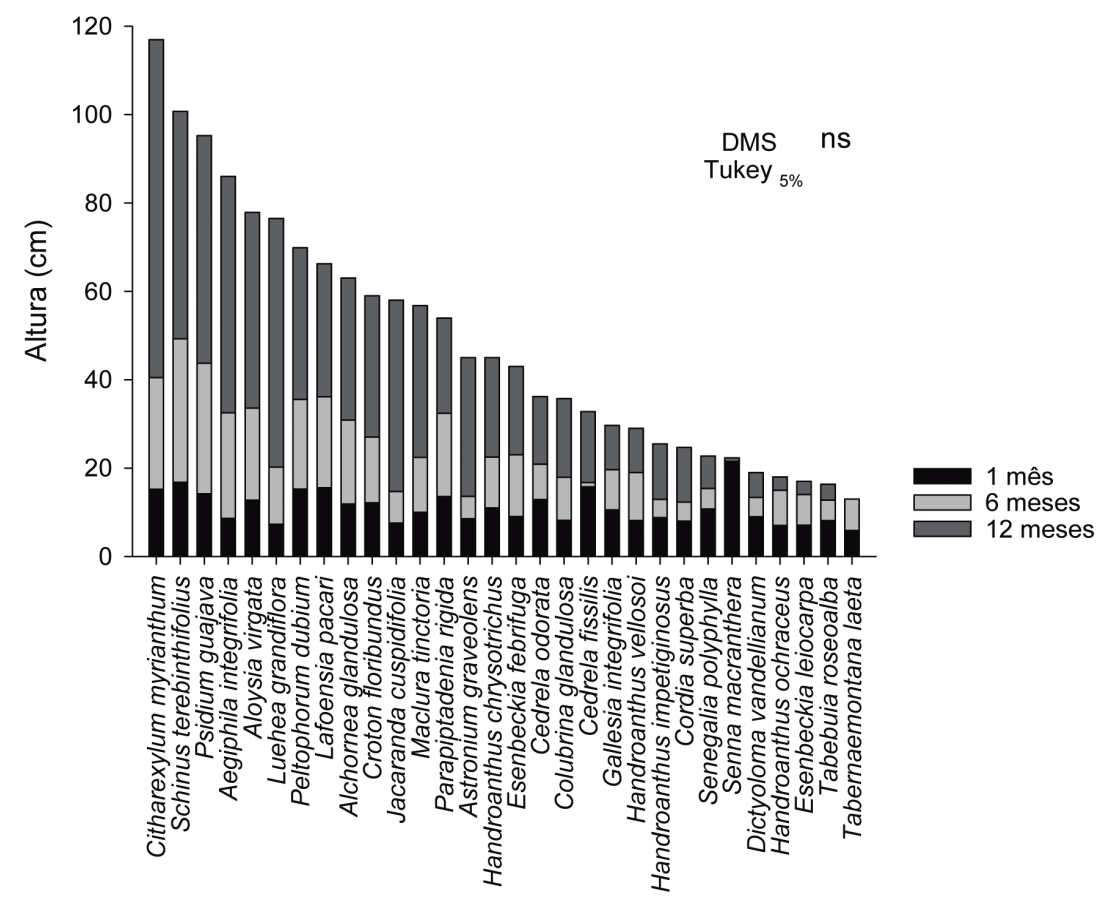

Figura 4. Média de alturas ao $1^{\circ}, 6^{\circ}$ e $12^{\circ}$ mês após o plantio, de 30 espécies arbóreas nativas, com mudas provenientes do recipiente bandeja. DMS (Tukey 5\%): não significativo.

Figure 4 . Average heights at the $1^{\text {st }}, 6^{\text {th }}$, and $12^{\text {th }}$ month after planting, from 30 native species, with seedlings from the container bandeja. LSD (Tukey 5\%): not significant

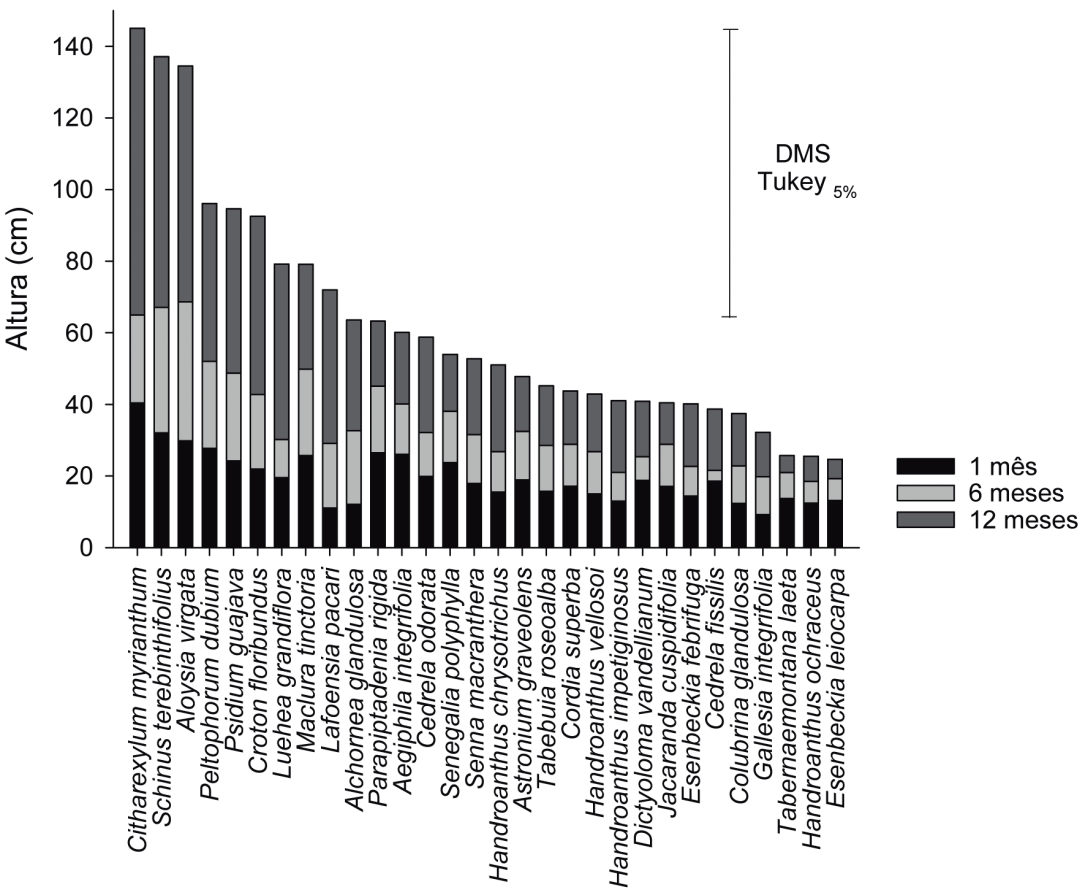

Figura 5. Média de alturas ao $1^{\circ}, 6^{\circ}$ e $12^{\circ}$ mês após o plantio, de 30 espécies arbóreas nativas, com mudas provenientes do recipiente tubetinho. DMS (Tukey $5 \%$ ) $=48,1 \mathrm{~cm}$.

Figure 5. Average heights at the $1^{\text {st }}, 6^{\text {th }}$, and $12^{\text {th }}$ month after planting, from 30 native species, with seedlings from the container tubetinho. LSD $($ Tukey $5 \%)=48.1 \mathrm{~cm}$ 


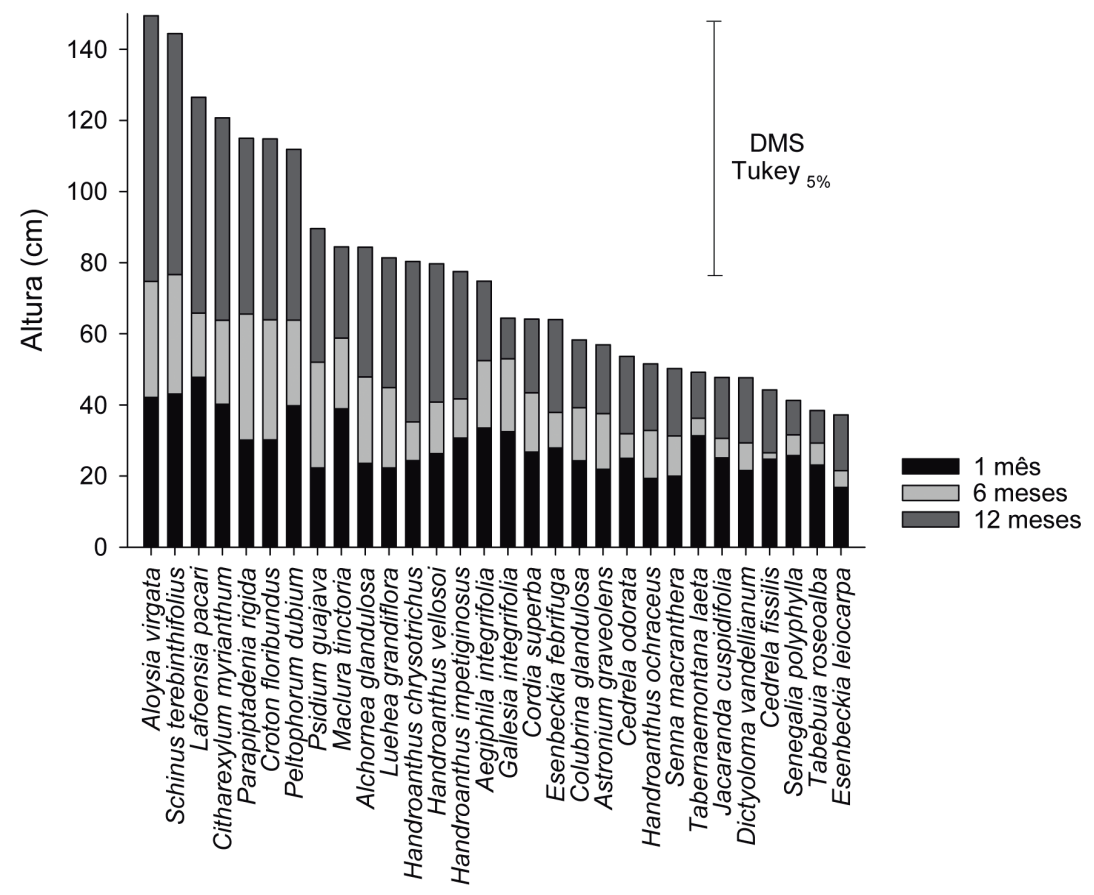

Figura 6. Média de alturas ao $1^{\circ}, 6^{\circ}$ e $12^{\circ}$ mês após o plantio, de 30 espécies arbóreas nativas, com mudas provenientes do recipiente tubetão. DMS (Tukey $5 \%)=42,7 \mathrm{~cm}$.

Figure 6 . Average heights at the $1^{\text {st }}, 6^{\text {th }}$, and $12^{\text {th }}$ month after planting, from 30 native species, with seedlings from the container tubetão. LSD $($ Tukey $5 \%)=42.7 \mathrm{~cm}$

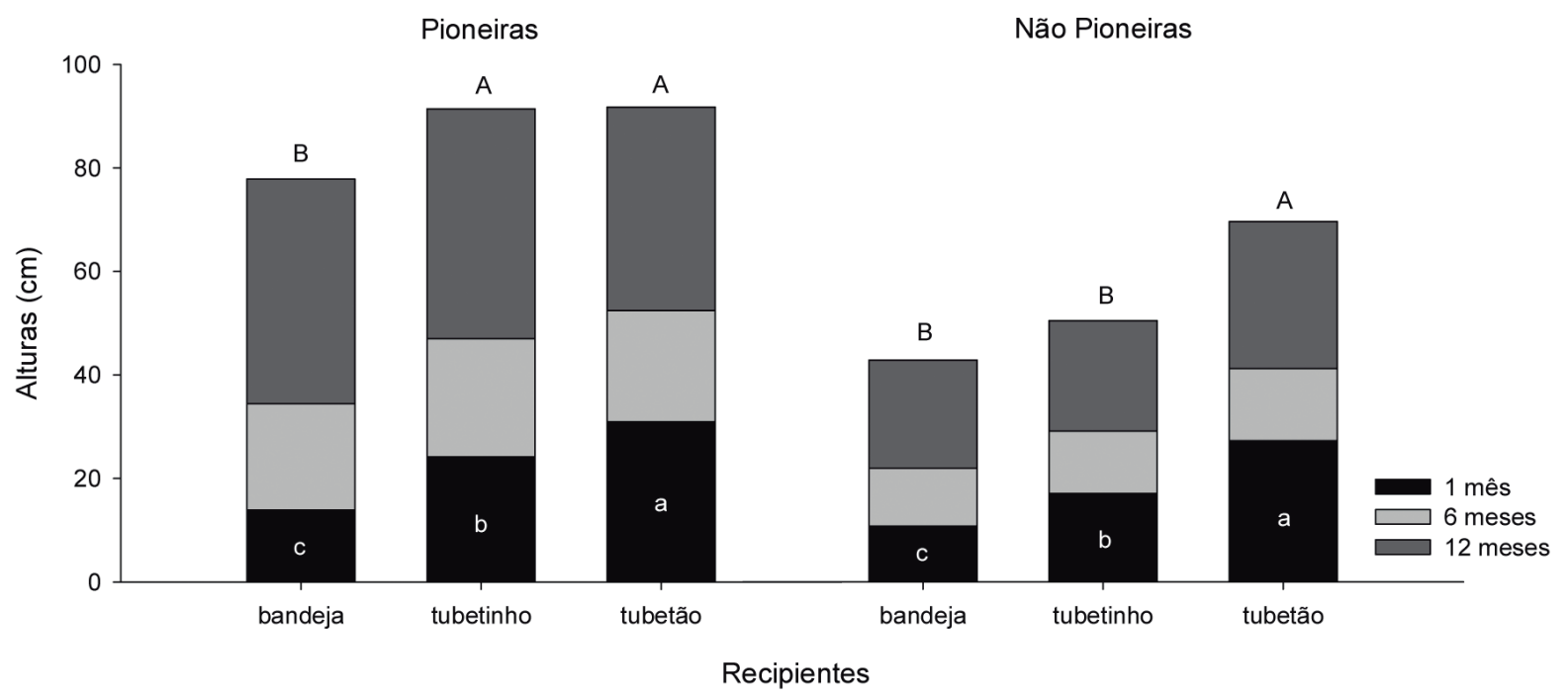

Figura 7 - Média de alturas ao $1^{\circ}, 6^{\circ}$ e $12^{\circ}$ mês após o plantio, dividindo as 30 espécies arbóreas nativas estudadas em dois subgrupos, pioneiras (P) e não pioneiras (NP), com os resultados apresentados para cada recipiente; as médias seguidas pelas mesmas letras (minúsculas) nas barras de mesma cor não diferem significativamente pelo teste de Tukey a 5\%, já as letras maiúsculas demonstram as diferenças apresentadas ao final do período de 12 meses.

Figure 7. Average heights at the $1^{\text {st }}, 6^{\text {th }}$, and $12^{\text {th }}$ month after planting, for 30 native tree species studied in two subgroups, pioneer $(\mathrm{P})$ and non-pioneers (NP), with results presented for each container. The means followed by the same letters (lowercase) in the same color bars do not differ significantly by Tukey test at 5\%. Capital letters show the differences presented at the end of 12 months. 
Tabela 10. Altura inicial, incremento em altura e altura final $(\mathrm{cm})$ de 30 espécies arbóreas nativas, nos recipientes (bandeja, tubetinho e tubetão), em três avaliações.

Table 10. Initial height, height increase, and final height $(\mathrm{cm})$ of 30 native species in three different containers (bandeja, tubetinho, and tubetão), during three evaluations.

\begin{tabular}{|c|c|c|c|c|}
\hline Recipientes & Altura no $1^{\circ}$ mês & $\begin{array}{c}\text { Incremento de altura } \\
1^{\circ} \text { ao } 6^{\circ} \text { mês }\end{array}$ & $\begin{array}{c}\text { Incremento de altura } \\
6^{\circ} \text { ao } 12^{\circ} \text { mês }\end{array}$ & $\begin{array}{c}\text { Altura total no } \\
12^{\circ} \text { mês }\end{array}$ \\
\hline \multicolumn{5}{|c|}{ Citharexylum myrianthum Cham. - pau-viola } \\
\hline bandeja & $15,2 \mathrm{~b}$ & $25,2 \mathrm{a}$ & $76,5 \mathrm{a}$ & 116,9 a \\
\hline tubetinho & $40,4 \mathrm{a}$ & $24,6 \mathrm{a}$ & $80,1 \mathrm{a}$ & $145,1 \mathrm{a}$ \\
\hline tubetão & $40,2 \mathrm{a}$ & $23,6 \mathrm{a}$ & 56,9 a & $120,7 \mathrm{a}$ \\
\hline \multicolumn{5}{|c|}{ Schinus terebinthifolius Raddi - aroeira-pimenteira } \\
\hline bandeja & $16,8 \mathrm{c}$ & $32,5 \mathrm{a}$ & $51,4 \mathrm{a}$ & $100,7 \mathrm{~b}$ \\
\hline tubetinho & $32,1 \mathrm{~b}$ & $35,0 \mathrm{a}$ & $70,0 \mathrm{a}$ & $137,1 \mathrm{ab}$ \\
\hline tubetão & $43,1 \mathrm{a}$ & $33,6 \mathrm{a}$ & $67,8 \mathrm{a}$ & $144,4 \mathrm{a}$ \\
\hline \multicolumn{5}{|c|}{ Aloysia virgata (Ruiz \& Pav.) Juss. - lixeira } \\
\hline bandeja & $12,8 \mathrm{c}$ & $20,8 \mathrm{a}$ & $44,3 \mathrm{a}$ & $77,8 \mathrm{c}$ \\
\hline tubetinho & $29,8 \mathrm{~b}$ & $38,8 \mathrm{a}$ & 65,9 a & $134,5 \mathrm{~b}$ \\
\hline tubetão & $42,1 \mathrm{a}$ & $32,7 \mathrm{a}$ & $74,7 \mathrm{a}$ & $149,4 \mathrm{a}$ \\
\hline \multicolumn{5}{|c|}{ Psidium guajava L. - goiaba } \\
\hline bandeja & $14,2 \mathrm{~b}$ & 29,6 a & $51,5 \mathrm{a}$ & $95,2 \mathrm{a}$ \\
\hline tubetinho & $24,2 \mathrm{a}$ & $24,5 \mathrm{~b}$ & $46,0 \mathrm{a}$ & 94,6 a \\
\hline tubetão & $22,3 \mathrm{a}$ & $29,7 \mathrm{a}$ & $37,6 \mathrm{a}$ & 89,6 a \\
\hline \multicolumn{5}{|c|}{ Peltophorum dubium (Spreng.) Taub. - canafístula } \\
\hline bandeja & $15,2 \mathrm{c}$ & $20,3 \mathrm{a}$ & $34,4 \mathrm{a}$ & $69,9 \mathrm{a}$ \\
\hline tubetinho & $27,8 \mathrm{~b}$ & $24,3 \mathrm{a}$ & $44,1 \mathrm{a}$ & $96,1 \mathrm{a}$ \\
\hline tubetão & $39,8 \mathrm{a}$ & $24,1 \mathrm{a}$ & $48,1 \mathrm{a}$ & $111,9 \mathrm{a}$ \\
\hline \multicolumn{5}{|c|}{ Croton floribundus Spreng. - capixingui } \\
\hline bandeja & $12,1 \mathrm{c}$ & $14,9 \mathrm{a}$ & $32,0 \mathrm{a}$ & $59,0 \mathrm{a}$ \\
\hline tubetinho & $21,9 \mathrm{~b}$ & $20,9 \mathrm{a}$ & $49,7 \mathrm{a}$ & $92,5 \mathrm{a}$ \\
\hline tubetão & $30,2 \mathrm{a}$ & $33,8 \mathrm{a}$ & 50,9 a & $114,8 \mathrm{a}$ \\
\hline \multicolumn{5}{|c|}{ Lafoensia pacari A.St.-Hil. - dedaleiro } \\
\hline bandeja & $15,6 \mathrm{~b}$ & $20,6 \mathrm{a}$ & $30,1 \mathrm{~b}$ & $66,2 \mathrm{~b}$ \\
\hline tubetinho & $11,1 \mathrm{~b}$ & $18,1 \mathrm{a}$ & $42,9 \mathrm{ab}$ & $72,0 \mathrm{~b}$ \\
\hline tubetão & $47,8 \mathrm{a}$ & $18,0 \mathrm{a}$ & $60,7 \mathrm{a}$ & $126,5 \mathrm{a}$ \\
\hline \multicolumn{5}{|c|}{ Luehea grandiflora Mart. Et Zucc. - açoita cavalo graúda } \\
\hline bandeja & $7,3 \mathrm{~b}$ & $12,9 \mathrm{a}$ & 56,3 a & $76,5 \mathrm{a}$ \\
\hline tubetinho & $19,5 \mathrm{a}$ & $10,7 \mathrm{a}$ & $49,0 \mathrm{a}$ & $79,2 \mathrm{a}$ \\
\hline tubetão & $22,3 \mathrm{a}$ & $22,6 \mathrm{a}$ & $36,5 \mathrm{a}$ & $81,4 \mathrm{a}$ \\
\hline \multicolumn{5}{|c|}{ Parapiptadenia rigida (Benth.) Brenan - guarucaia } \\
\hline bandeja & $13,6 \mathrm{~b}$ & $18,8 \mathrm{ab}$ & $21,5 \mathrm{a}$ & $53,9 \mathrm{~b}$ \\
\hline tubetinho & $26,5 \mathrm{a}$ & $18,6 \mathrm{~b}$ & $18,2 \mathrm{a}$ & $63,3 \mathrm{~b}$ \\
\hline tubetão & $30,1 \mathrm{a}$ & $35,4 \mathrm{a}$ & $49,4 \mathrm{a}$ & $114,9 \mathrm{a}$ \\
\hline \multicolumn{5}{|c|}{ Aegiphila integrifolia (Jacq.) Moldenke - tamanqueiro } \\
\hline bandeja & $8,6 \mathrm{~b}$ & $23,9 \mathrm{a}$ & $53,5 \mathrm{a}$ & 86,0 a \\
\hline tubetinho & $26,1 \mathrm{a}$ & $14,0 \mathrm{a}$ & $20,0 \mathrm{a}$ & $60,1 \mathrm{a}$ \\
\hline tubetão & 33,5 a & $18,9 \mathrm{a}$ & $22,4 \mathrm{a}$ & 74,8 a \\
\hline
\end{tabular}


Tabela 10 (continuação)

\begin{tabular}{|c|c|c|c|c|}
\hline Recipientes & Altura no $1^{\circ}$ mês & $\begin{array}{c}\text { Incremento de altura } \\
1^{\circ} \text { ao } 6^{\circ} \text { mês }\end{array}$ & $\begin{array}{c}\text { Incremento de altura } \\
6^{\circ} \text { ao } 12^{\circ} \text { mês }\end{array}$ & $\begin{array}{c}\text { Altura total no } \\
12^{\circ} \text { mês }\end{array}$ \\
\hline \multicolumn{5}{|c|}{ Maclura tinctoria (L.) D. Don ex Steud. - taiúva } \\
\hline bandeja & 10,0 & $12,4 \mathrm{a}$ & 34,4 a & $56,8 \mathrm{a}$ \\
\hline tubetinho & 25,7 & $24,2 \mathrm{a}$ & $29,3 \mathrm{a}$ & $79,1 \mathrm{a}$ \\
\hline tubetão & 38,9 & $19,9 \mathrm{a}$ & $25,7 \mathrm{a}$ & $84,4 \mathrm{a}$ \\
\hline \multicolumn{5}{|c|}{ Alchornea glandulosa Poepp. \& Endl. - tapiá } \\
\hline bandeja & $11,9 \mathrm{~b}$ & $19,0 \mathrm{a}$ & $32,1 \mathrm{a}$ & $63,0 \mathrm{a}$ \\
\hline tubetinho & $12,1 \mathrm{~b}$ & $20,6 \mathrm{a}$ & $30,9 \mathrm{a}$ & $63,6 \mathrm{a}$ \\
\hline tubetão & $23,5 \mathrm{a}$ & $24,3 \mathrm{a}$ & $36,5 \mathrm{a}$ & $84,3 \mathrm{a}$ \\
\hline \multicolumn{5}{|c|}{ Handroanthus chrysotrichus (Mart. ex DC.) Mattos - ipê-amarelo-cascudo } \\
\hline bandeja & $11,0 \mathrm{c}$ & $11,5 \mathrm{a}$ & $22,5 \mathrm{a}$ & $45,0 \mathrm{a}$ \\
\hline tubetinho & $15,5 \mathrm{~b}$ & $11,2 \mathrm{a}$ & $24,3 \mathrm{a}$ & $51,0 \mathrm{a}$ \\
\hline tubetão & $24,3 \mathrm{a}$ & $10,9 \mathrm{a}$ & $45,1 \mathrm{a}$ & 80,3 a \\
\hline \multicolumn{5}{|c|}{ Handroanthus vellosoi (Toledo) Mattos - ipê-amarelo-liso } \\
\hline bandeja & $8,1 \mathrm{c}$ & $10,9 \mathrm{a}$ & $10,0 \mathrm{a}$ & $29,0 \mathrm{~b}$ \\
\hline tubetinho & $15,0 \mathrm{~b}$ & $11,8 \mathrm{a}$ & $16,1 \mathrm{a}$ & $42,9 \mathrm{a}$ \\
\hline tubetão & $26,3 \mathrm{a}$ & $14,5 \mathrm{a}$ & $38,9 \mathrm{a}$ & $79,7 \mathrm{a}$ \\
\hline \multicolumn{5}{|c|}{ Astronium graveolens Jacq. - guaritá } \\
\hline bandeja & $8,6 \mathrm{~b}$ & $5,0 \mathrm{~b}$ & $31,4 \mathrm{a}$ & $45,0 \mathrm{a}$ \\
\hline tubetinho & $18,9 \mathrm{a}$ & $13,6 \mathrm{ab}$ & $15,3 \mathrm{a}$ & $47,8 \mathrm{a}$ \\
\hline tubetão & $21,9 \mathrm{a}$ & $15,6 \mathrm{a}$ & $19,4 \mathrm{a}$ & $56,9 \mathrm{a}$ \\
\hline \multicolumn{5}{|c|}{ Cedrela odorata L. - cedro-do-brejo } \\
\hline bandeja & $12,9 \mathrm{c}$ & $8,0 \mathrm{a}$ & $15,3 \mathrm{~b}$ & $36,2 b$ \\
\hline tubetinho & $19,9 \mathrm{~b}$ & $12,3 \mathrm{a}$ & $26,6 \mathrm{a}$ & $58,8 \mathrm{a}$ \\
\hline tubetão & $25,0 \mathrm{a}$ & $6,9 \mathrm{a}$ & $21,8 \mathrm{ab}$ & $53,7 \mathrm{a}$ \\
\hline \multicolumn{5}{|c|}{ Esenbeckia febrifuga (A.St.-Hil.) A. Juss. ex Mart. - crumarim } \\
\hline bandeja & $9,0 \mathrm{c}$ & $14,0 \mathrm{a}$ & $20,0 \mathrm{a}$ & $43,0 \mathrm{a}$ \\
\hline tubetinho & $14,4 \mathrm{~b}$ & $8,2 \mathrm{a}$ & $17,5 \mathrm{a}$ & $40,2 \mathrm{a}$ \\
\hline tubetão & $27,9 \mathrm{a}$ & $10,0 \mathrm{a}$ & $26,1 \mathrm{a}$ & $64,0 \mathrm{a}$ \\
\hline \multicolumn{5}{|c|}{ Jacaranda cuspidifolia Mart. - jacarandá-branco } \\
\hline bandeja & $7,6 \mathrm{c}$ & $7,1 \mathrm{a}$ & $43,3 \mathrm{a}$ & $58,0 \mathrm{a}$ \\
\hline tubetinho & $17,1 \mathrm{~b}$ & $11,7 \mathrm{a}$ & $11,6 \mathrm{a}$ & $40,5 \mathrm{a}$ \\
\hline tubetão & $25,1 \mathrm{a}$ & $5,5 \mathrm{a}$ & $17,2 \mathrm{a}$ & $47,8 \mathrm{a}$ \\
\hline \multicolumn{5}{|c|}{ Handroanthus impetiginosus Mattos - ipê-roxo } \\
\hline bandeja & $8,8 \mathrm{c}$ & $4,2 \mathrm{a}$ & $12,6 \mathrm{~b}$ & $25,5 \mathrm{~b}$ \\
\hline tubetinho & $13,0 \mathrm{~b}$ & $8,1 \mathrm{a}$ & $20,0 \mathrm{ab}$ & $41,1 \mathrm{~b}$ \\
\hline tubetão & $30,7 \mathrm{a}$ & $11,0 \mathrm{a}$ & $35,8 \mathrm{a}$ & $77,5 \mathrm{a}$ \\
\hline \multicolumn{5}{|c|}{ Cordia superba Cham. - babosa-branca } \\
\hline bandeja & $8,0 \mathrm{c}$ & $4,3 \mathrm{~b}$ & $12,4 \mathrm{a}$ & $24,7 \mathrm{~b}$ \\
\hline tubetinho & $17,2 \mathrm{~b}$ & $11,7 \mathrm{ab}$ & $14,9 \mathrm{a}$ & $43,7 \mathrm{ab}$ \\
\hline tubetão & $26,8 \mathrm{a}$ & $16,7 \mathrm{a}$ & $20,7 \mathrm{a}$ & $64,1 \mathrm{a}$ \\
\hline
\end{tabular}




\section{Tabela 10 (continuação)}

\begin{tabular}{|c|c|c|c|c|}
\hline Recipientes & Altura no $1^{\circ}$ mês & $\begin{array}{c}\text { Incremento de altura } \\
1^{\circ} \text { ao } 6^{\circ} \text { mês }\end{array}$ & $\begin{array}{c}\text { Incremento de altura } \\
6^{\circ} \text { ao } 12^{\circ} \text { mês }\end{array}$ & $\begin{array}{c}\text { Altura total no } \\
12^{\circ} \text { mês }\end{array}$ \\
\hline \multicolumn{5}{|c|}{ Colubrina glandulosa Perkins - sobrasil } \\
\hline bandeja & $8,2 \mathrm{~b}$ & $9,8 \mathrm{~b}$ & $17,8 \mathrm{a}$ & $35,7 \mathrm{a}$ \\
\hline tubetinho & $12,3 \mathrm{~b}$ & $10,5 \mathrm{ab}$ & $14,6 \mathrm{a}$ & $37,4 \mathrm{a}$ \\
\hline tubetão & $24,3 \mathrm{a}$ & $14,9 \mathrm{a}$ & $19,0 \mathrm{a}$ & $58,3 \mathrm{a}$ \\
\hline \multicolumn{5}{|c|}{ Gallesia integrifolia (Spreng.) Harms - pau-d'alho } \\
\hline bandeja & $10,5 \mathrm{~b}$ & $9,1 \mathrm{a}$ & $10,0 \mathrm{a}$ & $29,7 \mathrm{a}$ \\
\hline tubetinho & $9,2 \mathrm{~b}$ & $10,6 \mathrm{a}$ & $12,4 \mathrm{a}$ & $32,2 \mathrm{a}$ \\
\hline tubetão & $32,5 \mathrm{a}$ & $20,5 \mathrm{a}$ & $11,4 \mathrm{a}$ & $64,4 \mathrm{a}$ \\
\hline \multicolumn{5}{|c|}{ Senna macranthera (DC. ex Collad.) H.S.Irwin \& Barneby - manduirana } \\
\hline bandeja & 22,3 & $-0,1 \mathrm{a}$ & $-0,8 \mathrm{a}$ & $21,4 \mathrm{a}$ \\
\hline tubetinho & 17,9 & $13,6 \mathrm{a}$ & $21,2 \mathrm{a}$ & $52,7 \mathrm{a}$ \\
\hline tubetão & 20,0 & $11,3 \mathrm{a}$ & $18,9 \mathrm{a}$ & $50,2 \mathrm{a}$ \\
\hline \multicolumn{5}{|c|}{ Senegalia polyphylla (DC.) Britton \& Rose - monjoleiro } \\
\hline bandeja & $10,8 \mathrm{~b}$ & $4,7 \mathrm{a}$ & $7,3 \mathrm{a}$ & $22,7 \mathrm{~b}$ \\
\hline tubetinho & $23,7 \mathrm{a}$ & $14,3 \mathrm{a}$ & 15,9 a & $54,0 \mathrm{a}$ \\
\hline tubetão & $25,8 \mathrm{a}$ & $5,8 \mathrm{a}$ & $9,6 \mathrm{a}$ & $41,3 \mathrm{ab}$ \\
\hline \multicolumn{5}{|c|}{ Cedrela fissilis Vell. - cedro-rosa } \\
\hline bandeja & $15,8 \mathrm{~b}$ & $0,9 \mathrm{a}$ & $16,1 \mathrm{a}$ & $32,8 \mathrm{a}$ \\
\hline tubetinho & $18,6 \mathrm{ab}$ & $3,0 \mathrm{a}$ & $17,1 \mathrm{a}$ & $38,7 \mathrm{a}$ \\
\hline tubetão & $24,7 \mathrm{a}$ & $1,8 \mathrm{a}$ & $17,7 \mathrm{a}$ & $44,2 \mathrm{a}$ \\
\hline \multicolumn{5}{|c|}{ Dictyoloma vandellianum A. Juss. - tingui } \\
\hline bandeja & $9,0 \mathrm{~b}$ & $4,4 \mathrm{a}$ & $5,6 \mathrm{a}$ & $19,0 \mathrm{~b}$ \\
\hline tubetinho & $18,8 \mathrm{a}$ & $6,6 \mathrm{a}$ & $15,5 \mathrm{a}$ & $40,9 \mathrm{ab}$ \\
\hline tubetão & $21,6 \mathrm{a}$ & $7,7 \mathrm{a}$ & $18,4 \mathrm{a}$ & $47,7 \mathrm{a}$ \\
\hline \multicolumn{5}{|c|}{ Tabebuia roseoalba (Ridl.) Sandwith - ipê-branco } \\
\hline bandeja & $8,1 \mathrm{c}$ & $4,6 \mathrm{a}$ & $3,6 \mathrm{a}$ & $16,3 \mathrm{~b}$ \\
\hline tubetinho & $15,7 \mathrm{~b}$ & $12,8 \mathrm{a}$ & $16,7 \mathrm{a}$ & $45,2 \mathrm{a}$ \\
\hline tubetão & $23,1 \mathrm{a}$ & $6,2 \mathrm{a}$ & $9,2 \mathrm{a}$ & $38,4 \mathrm{ab}$ \\
\hline \multicolumn{5}{|c|}{ Handroanthus ochraceus (Cham.) Mattos - ipê-amarelo } \\
\hline bandeja & $7,0 \mathrm{~b}$ & $8,0 \mathrm{a}$ & $3,0 \mathrm{a}$ & $18,0 \mathrm{~b}$ \\
\hline tubetinho & $12,4 \mathrm{ab}$ & $6,1 \mathrm{a}$ & $7,0 \mathrm{a}$ & $25,5 \mathrm{~b}$ \\
\hline tubetão & $19,3 \mathrm{a}$ & $13,5 \mathrm{a}$ & $18,7 \mathrm{a}$ & $51,5 \mathrm{a}$ \\
\hline \multicolumn{5}{|c|}{ Tabernaemontana laeta Mart.- leiteiro } \\
\hline bandeja & $5,9 \mathrm{c}$ & $7,1 \mathrm{a}$ & $0 \mathrm{a}$ & $13,0 \mathrm{c}$ \\
\hline tubetinho & $13,7 \mathrm{~b}$ & $7,2 \mathrm{a}$ & $4,7 \mathrm{a}$ & $25,7 \mathrm{~b}$ \\
\hline tubetão & $31,3 \mathrm{a}$ & $4,9 \mathrm{a}$ & $12,9 \mathrm{a}$ & $49,2 \mathrm{a}$ \\
\hline \multicolumn{5}{|c|}{ Esenbeckia leiocarpa Engl. - guarantã } \\
\hline bandeja & $7,1 \mathrm{c}$ & $6,9 \mathrm{a}$ & $3,0 \mathrm{a}$ & $17,0 \mathrm{a}$ \\
\hline tubetinho & $13,2 \mathrm{~b}$ & $6,1 \mathrm{a}$ & $5,4 \mathrm{a}$ & $24,7 \mathrm{a}$ \\
\hline tubetão & $16,9 \mathrm{a}$ & $4,7 \mathrm{a}$ & $15,7 \mathrm{a}$ & $37,2 \mathrm{a}$ \\
\hline
\end{tabular}

*Médias seguidas pelas mesmas letras na vertical não diferem significativamente pelo teste de Tukey a 5\%.* 
Assim, para as condições encontradas neste experimento, quatro espécies classificadas como não pioneiras (Lafoensia pacari, Luehea grandiflora, Parapiptadenia rigida e Maclura tinctoria), apresentaram-se com o crescimento similar às pioneiras; e cinco espécies classificadas inicialmente como pioneiras (Cordia superba, Senna macranthera, Senegalia polyphylla, Dictyoloma vandellianum e Tabernaemontana laeta) apresentaram crescimento similar ao obtido por não pioneiras.

\section{Conclusões}

As mudas oriundas do recipiente tubetão obtiveram as menores porcentagens de mortalidade, seguidas de tubetinho e bandeja, entretanto algumas espécies produzidas na bandeja mostraram-se com índices de mortalidade menores, se comparadas a outras espécies provenientes de tubetinhos, apresentando assim possibilidades de uso, desde que adotados manejos diferenciados (irrigação pós-plantio e controle de competidores) visando a garantir o aumento da sobrevivência inicial das mudas.

O hidrogel não interferiu no estabelecimento e nem no crescimento das mudas nos diferentes tratamentos, para o período em que o experimento foi avaliado, onde não houve déficit hídrico registrado.

Quanto ao desenvolvimento das mudas em crescimento e incremento de altura, pode-se concluir que, uma vez garantido o estabelecimento das mudas, mesmo com manejos diferenciados (irrigação após o plantio e maior cuidado no controle de gramíneas competidoras nos primeiros meses), não há diferenças entre os recipientes.

\section{Literatura Citada}

Angiosperm Phylogeny Group II. 2003. An update of the angiosperm phylogeny group classification for the orders and families of flowering plants: APG II. Botanical Journal of the Linnean Society 141: 399-436.

Atlas Ambiental do Município de São Paulo. 2002. Secretaria do Verde e do Meio Ambiente - SVMA/ PMSP Secretaria de Planejamento - SEMPLA/PMSP 118 - Mapa Geológico sobre Imagem Sombreada de Relevo. Prefeitura Municipal de São Paulo, São Paulo.

Azevedo, T.L.F. 2000. Avaliação da eficiência do polímero agrícola de poliacrilamida no fornecimento de água para o cafeeiro (Coffea arabica L) cv. Tupi. Dissertação de Mestrado, Universidade Estadual de Maringá, Maringá.

Barbosa, L.M., Martins, S.E. 2003. Diversificando o reflorestamento no Estado de São Paulo: espécies disponíveis por região e ecossistema. (Manual 10). IBt/ SMA, São Paulo.
Barros, N.F., Brandi, R.M., Couto, L. \& Rezende, G.C. 1978. Efeitos de recipientes na sobrevivência e no crescimento de mudas de Eucalyptus grandis no viveiro e no campo. Revista Árvore 2: 141-151.

Besagoitia, M.C.R. 1980. Efecto del tamaño de la bolsa en el desarrollo del cafetos cultirares 'Bourbon' y 'Pacas' em vivero. Resúmenes de Invetigaciones em Café 3: 71-72.

Brancalion, P.H.S., Rodrigues, R.R., Gandolfi, S., Kageyama, P.Y., Nave, A.G., Gandara, F.B., Barbosa, L.M. \& Tabarelli, M. 2010. Instrumentos legais podem contribuir para a restauração de florestas tropicais biodiversas. Revista Árvore 34: 455-470.

Buzetto, F.A., Bizon, J.M.C. \& Seixas, F. 2002. Avaliação de polímero adsorvente à base fromacrilamida no fornecimento de água para mudas de Eucalyptus urophylla em pós-plantio. (Circular Técnica 195). IPEF, Piracicaba.

Carneiro, J.G.A. 1987. Influência de recipientes e de estações de semeadura sobre o comportamento do sistema radicular e dos parâmetros morfológicos de mudas de Pinus taeda e Pinus elliottii L. Tese de Doutorado, Universidade Federal do Paraná, Curitiba.

Catharino, E.L.M., Bernacci, L.C., Franco, G.A.D.C., Durigan, G. \& Metzger, J.P. 2006. Aspectos da composição e diversidade do componente arbóreo das florestas da Reserva Florestal do Morro Grande, Cotia, SP. Biota Neotropica 6.

Flannery, R.L. \& Busscher, W.J. 1982. Use of a synthetic polymer in potting soil to improve water holding capacity. Communication in Soil Science and Plant Analysis 13: 103-111.

FUSP. Plano da Bacia Hidrográfica do Alto Tietê. Relatório Final. Fundação Apoio à Universidade de São Paulo. v.1. Universidade de São Paulo, São Paulo.

Godoy Junior, C. 1965. Café, mudas em recipientes de polietileno. Revista de Agricultura 40: 161-166.

Gomes, J.M., Pereira, A.R. \& Souza, A.L. 1980. Influência do tamanho da embalagem plástica na produção de mudas de Pinus caribaea var. hondurensis. (Boletim Técnico 9). SIF, Viçosa.

Gomes, J.M.,Pereira, A.R., Rezende, G.C. \& Maciel, L.A. 1981. Efeito do tamanho de recipientes plásticos na formação de florestas de eucaliptos. Boletim Técnico Sociedade de Investigações Florestais 4: 1-12.

Gomes, J.M., Couto, L., Borges, R. C.G. \& Freitas, S.C. 1990. Influência do tamanho da embalagem plástica na produção de mudas de Ipê (Tabebuia serratifolia), de Copaíba (Copaifera langsdorffii) e de Angico Vermelho (Piptadenia peregrina). Revista Árvore 14: 26-34.

Gomes, J.M., Couto, L., Leite, H.G., Xavier, A. \& Garcia, S.L.R. 2003. Crescimento de mudas de Eucalyptus grandis em diferentes tamanhos de tubetes e fertilização N-P-K. Revista Árvore 27: 113-127. 
Hartmann, H.T. \& Kester, D.E. 2002. Plant propagation: principles and practices. 7 ed. New Jersey: PrenticeHall.

Henderson, J.C. \& Hensley, D.L. 1986. Efficacy of a hydrophilic gel as a transplant aid. Horticulture Science 21: 991-992.

Lamont, G.P. \& O'Connell, M.A. 1987. Shelf-life of bedding plants as influenced by potting media and hydrogels. Scientia Horticulturae 31: 141-149.

Lima, R.L.S., Severino, L.S., Silva, M.I.L.,Vale, L.S. \& Beltrão, N.E.M. 2006. Volume de recipiente e composição de substrato para produção de mudas de mamoneira. Ciência Agrotécnica 30: 480-486.

Macedo, M. O., Campello, E. F. C., Andrade, A. G., Gamma, M. J. E. C., Buzato, L. \& Faria, S. M. 2003. Resposta de leguminosas arbóreas à adição de hidrogel nas covas de um plantio em escória de siderúrgica de alto-forno. In: $29^{\circ}$ Congresso Brasileiro de Ciência do Solo, Ribeirão Preto. pp. 4.

Nave, A.G. \& Rodrigues, R.R. 2007. Combination os species into filing and diversity groups as forest restoration methodology. In: R.R. Rodrigues, S.V. Martins. \& S. Gandolfi. High diversity forest restoration in degraded areas: Methods and projects in Brazil. Nova Science Publishers, New York, pp. 103-126.

Nimah, N.M., Ryan, J. \& Chaudhry, M.A. 1983. Effect of synthetic conditioners on soil water retention, hydraulic conductivity, porosity, and aggregation. Soil Science Society of America Journal 47: 742-745.

Ribeiro, M.C., Metzger, J.P., Martensen, A.C., Ponzoni, F.J. \& Hirota, M.M. 2009. The Brazilian Atlantic Forest: How much is left, and how is the remaining forest distributed. Implications for conservation. Biological Conservation 142: 1141-1153.

Rodrigues, R.R. \& Gandolfi, S. 2004. Conceitos, tendências e ações para a recuperação de florestas ciliares. In: R.R. Rodrigues \& H.F. Leitão-Filho. Matas ciliares: conservação e recuperação. EDUSP, São Paulo, pp. 91-99.

SAS Institute. 2007. SAS user's guide: statistics version 9.2. SAS Institute, Cary.
Silveira, A.J., Santana, D.P. \& Pereira, M.L. 1973. Efeito do tamanho do saco plástico e do método de semeadura no desenvolvimento de mudas de café. Seiva 33: 14-18.

Souza, C.A., Oliveira, R.B., Martins Filho, S. \& Lima, J.S.S. 2006. Crescimento em campo de espécies florestais em diferentes condições de adubações. Ciência Florestal 16: 243-249.

Souza, P.V.D. 1995. Optimización de le produccion de plantones de cítricos en vivero: inoculación com mícorrizas vesiculares arbusculares. Tesis Doctoral, Universidad Politécnica de Valencia, Valencia.

Souza, R.P. \& Valio, I.F.M. 2003. Seedling growth of fifteen Brazilian tropical tree species differing in successional status. Revista Brasileira de Botânica 26: 35-47.

Sparovek, G., Lier, Q.J.V. \& Neto, D.D. 2007. Computer assisted Koeppen climate Classification: a case sutdy for Brazil. International Journal of Climatology 27: 257-266.

Spurr, S.H. \& Barnes, B.V. 1982. Ecologia florestal. AGT, México.

Vale, G.F.R., Carvalho, S.P. \& Paiva, L.C. 2006. Avaliação da eficiência de polímeros hidroretentores no desenvolvimento do cafeeiro em pós-plantio. Coffee Science 1: 7-13.

Viani, R.A.G. \& Rodrigues, R.R. 2008. Impacto da remoção de plântulas sobre a estrutura da comunidade regenerante de Floresta Estacional Semidecicual. Acta Botanica Brasilica 22: 1015-1026.

Vianna, A.C.C. 1964. Desenvolvimento de mudas de café em bolsas de polietileno. Ciência e Cultura 16: 142-143.

Vlach, T.R. 1991. Creeping bentgrass responses to water absorbing polymers in simulated golf greens (online). Wisconsin, Aug. http://archive.lib.msu.edu/tic/groot/ article/1990jul34.pdf. (acesso em 28.5.2011).

Wendling, I. \& Gatto, A. 2002. Substratos, adubação e irrigação na produção de mudas. Aprenda Fácil Editora, Viçosa.

Whitmore, T.C. 1989. Changes over twenty-one years in the Kolombangara rain forests. Journal of Ecology 77: 469-483.

Zar, J.H. 1999. Biostatistical analyses. 4rd ed. PrenticeHall, Upper Saddle River. 